\title{
A Welfare Analysis of Macroprudential Policy Rules in the Euro Area
}

\author{
Jean-Christophe Poutineau* Gauthier Vermandel ${ }^{\dagger}$
}

2016

\begin{abstract}
In an estimated DSGE model of the European Monetary Union that accounts for financial differences between core and peripheral countries, we find that country-adjusted macroprudential measures lead to significant welfare gains with respect to a uniform macroprudential policy rule that reacts to union-wide financial developments. However, peripheral countries are the winners from the implementation of macroprudential measures while core countries incur welfare losses, thus questioning the interest of adopting coordinated macroprudential measures with peripheral countries.
\end{abstract}

JEL classification: E32; E44; E52; F36; F41;

Keywords: Macroprudential policy, Euro Area, Financial Accelerator, DSGE TwoCountry Model, Bayesian Estimation

We thank Jean-Pierre Allegret, Miguel Casares, Jean-Bernard Chatelain, Laurent Clerc, Patrick Fève, Manuel F. Martins, Samuel Maveyraud, Tovonony Razafindrabe, Marc-Alexandre Sénégas and Raf Wouters for remarks and discussions on previous versions. We remain responsible for any errors and omissions.

${ }^{*}$ CREM, UMR CNRS 6211, Université de Rennes I, Rennes, France. E-mail: jeanchristophe.poutineau@univ-rennes1.fr.

${ }^{\dagger}$ Department of Economics, University Paris-Dauphine, Paris, France. E-mail: gauthier@vermandel.fr. Corresponding author. 


\section{Introduction}

As broadly defined by Galati and Moessner (2013), "macroprudential policy is seen as aiming at financial stability". This policy contributes to the stability of the financial system both in promoting measures that enhance the resilience of the financial system and counteract the emergence of financial imbalances. If initially macroprudential actions have been associated with countercyclical capital requirements for financial intermediaries, they now encompass a wider range of practices. Furthermore, since the recent financial crisis of 2007, macroprudential policies have been considered as a natural complement to monetary policy actions to prevent and offset the destabilizing consequences of financial fluctuations.

Besides the choice of adequate instruments, the definition of macroprudential measures in European countries hinges on the balance that should be reached between national and federal concerns. As an integrated economic area, the Eurozone as a whole should require a homogenous treatment for all participating countries. Nevertheless, some remaining structural heterogeneities give rise to diverging financial cycles across Eurosystem participants, questioning the interest of lifting up this policy to a federal level as monetary policy. Consequently, the conduct of macroprudential policy in the Euro Area should account for imperfections related to the financial environment as well as asymmetries in the credit cycles between country members.

Following the De Larosière (2009) report, countries belonging to the European Union (and by so, the Eurozone) have adopted a federal organization for the conduct of macroprudential policies taking into account national heterogeneities. Currently, supervisory and regulatory frameworks remain fragmented along national lines, while international coordination is achieved through the European Systemic Risk Board (ESRB). This operational scheme is in sharp contrast to monetary policy principles, as the Eurozone monetary stance only reacts to union-wide aggregates.

The aim of this paper is to quantify the welfare gains that could be obtained within this institutional organization through a coordinated implementation of macroprudential policy tailored to national situations. We more particularly build and estimate a two-region DSGE model of the EMU that accounts for financial differences between core and peripheral countries to determine how union-wide and regional concerns should be balanced regarding the choice of both the financial variable to be targeted and the value of the macroprudential policy parameters. Macroprudential policy is introduced without microfoundations through a tax on corporate loans which reacts to credit growth to dampen credit cycles.

Our analysis shares some common features with recent analyzes surveyed by Loisel (2014). The analysis of Quint and Rabanal (2014) provides a natural point of departure for this paper, as it develops a two-country DSGE model well suited to the case of the Eurozone. Quint and Rabanal (2014) study the optimal policy mix needed within a currency union, where country-specific boom and bust cycles cannot be directly addressed with monetary policy. Accounting for regional heterogeneities in the Eurozone they find that the coordination of monetary and macroprudential policies stabilizes the effect of real and financial shocks to the macro-environment. Focusing on the interaction between financial and housing cycles, they find that macro- 
prudential policy leads to significant gains for households in terms of unconditional consumption. Macroprudential policy is introduced through an ad hoc tax on housing loans which aims at offsetting financial imbalances created by a financial accelerator mechanism between impatient households and financial intermediaries. They also find that there are no negative spillover effects of regulation from one member state to another, so setting macroprudential policies at the regional or union-wide levels will therefore not change the outcome.

This paper differs from Quint and Rabanal (2014) on three major aspects. First, their model includes a financial accelerator mechanism on the household side, such that changes in the balance sheet of borrowers due to house-price fluctuations affect the spread between lending and deposit rates. In contrast, we focus on the productive side of the economy (namely firms and entrepreneurs) and consider the link between investors and the banking system as the main channel for the build-up of financial imbalances. In our setting, we assume that entrepreneurs' optimism gives rise to a financial accelerator phenomenon that amplifies the transmission of shocks in the economy through the external finance premium. These biased expectations lead entrepreneurs to default on their loans, creating an important inefficiency in the economy. Second, we will not study the optimal policy mix between monetary and macroprudential policies. Third, Quint and Rabanal (2014) limit their analysis to macroprudential policy rules based on domestic loan developments. We take another complementary focus by evaluating whether macroprudential policy should react to regional or union-wide developments of the loan growth rate. Given the synchronization of business cycles between EMU participants, reacting to unionwide developments could be more effective in dampening financial cycles and avoiding negative spillovers. In our setting, the individual treatment of each area in the macroprudential action is assessed along two complementary dimensions related to the variables to which policy reacts (union-wide or regional lending developments) and to the policy stance (regional or uniform macroprudential parameter setting). Our experiments confirm the findings of Quint and Rabanal (2014) in the sense that the best outcome from macroprudential actions is obtained by reacting to regional developments.

The methodology employed in this paper comprises three steps: (i) we estimate a two-region DSGE model for the Euro Area with only monetary policy (as there are no observations for an estimation of a macroprudential rule); (ii) we compute the optimal policy rules (both monetary and macroprudential policy) given the estimated parameters assuming a two-stage game where monetary policy is the leader; (iii) we compare the welfare implications of having homogenous versus heterogeneous macroprudential rules across regions of the Eurosystem using the optimal Taylor rule as our benchmark reference. ${ }^{1}$

Our main results clearly show that it is always preferable, from the point of view of the union, to make the macroprudential instruments react to regional developments. In particular, we find that in this case macroprudential measures lead to

\footnotetext{
${ }^{1}$ We are aware that a limitation of our approach lies in the fact that the estimated model does not include macroprudential policy and is then different from the optimal setup in which we compare counterfactual macroprudential rules. However, this methodology is largely used in macroprudential policy research papers (see for instance Darracq-Pariès et al. (2011); Quint and Rabanal (2014); Angelini et al. (2014)).
} 
higher welfare gains at the Eurozone level representing $0.0372 \%$ of permanent consumption instead of $0.0235 \%$ under macroprudential measures reacting to unionwide developments. Thus, in terms of policy implications, our experiments reveal that macroprudential policy should be adjusted to regional evolutions, confirming the current institutional framework adopted in the Euro Area based on regional macroprudential measures. However, the welfare gains obtained at the union-wide level are unequally shared between participating countries. We find that peripheral countries are the main winners in the conduct of macroprudential policy while welfare improvements are rather limited for core countries.

The paper is organized as follows. The following two sections sketch the model: section 2 presents the private sector and section 3 the policy organization and the general equilibrium of the model. section 4 presents the data, the econometric approach and reports the estimates. section 5 discusses the welfare consequences of alternative governance schemes for macroprudential measures. section 6 concludes.

\section{The private sector}

The general structure of the model is depicted in Figure 1. The Eurozone is presented as a two-country DSGE model made of two asymmetric areas $i \in\{c, p\}$ (where $c$ is for core and $p$ for periphery parts) of relative sizes $n_{c}$ and $n_{p}$. The size of each sector is normalized to 1 . Each part of the monetary union is populated by consumers, intermediate and final producers, entrepreneurs, capital suppliers and a banking system.

Each economy is populated by households, intermediate and final firms, entrepreneurs and a banking system. Households consume final goods and supply labor to firms. The intermediate sector produces intermediate goods that are combined by final firms to become final goods. Following Bernanke et al. (1999), entrepreneurs bring to intermediates firms the physical capital involved in the production process of goods. The entrepreneur is a key agent to introduce financial frictions as it contracts loans to financial intermediaries and can endogenously default on its loans.

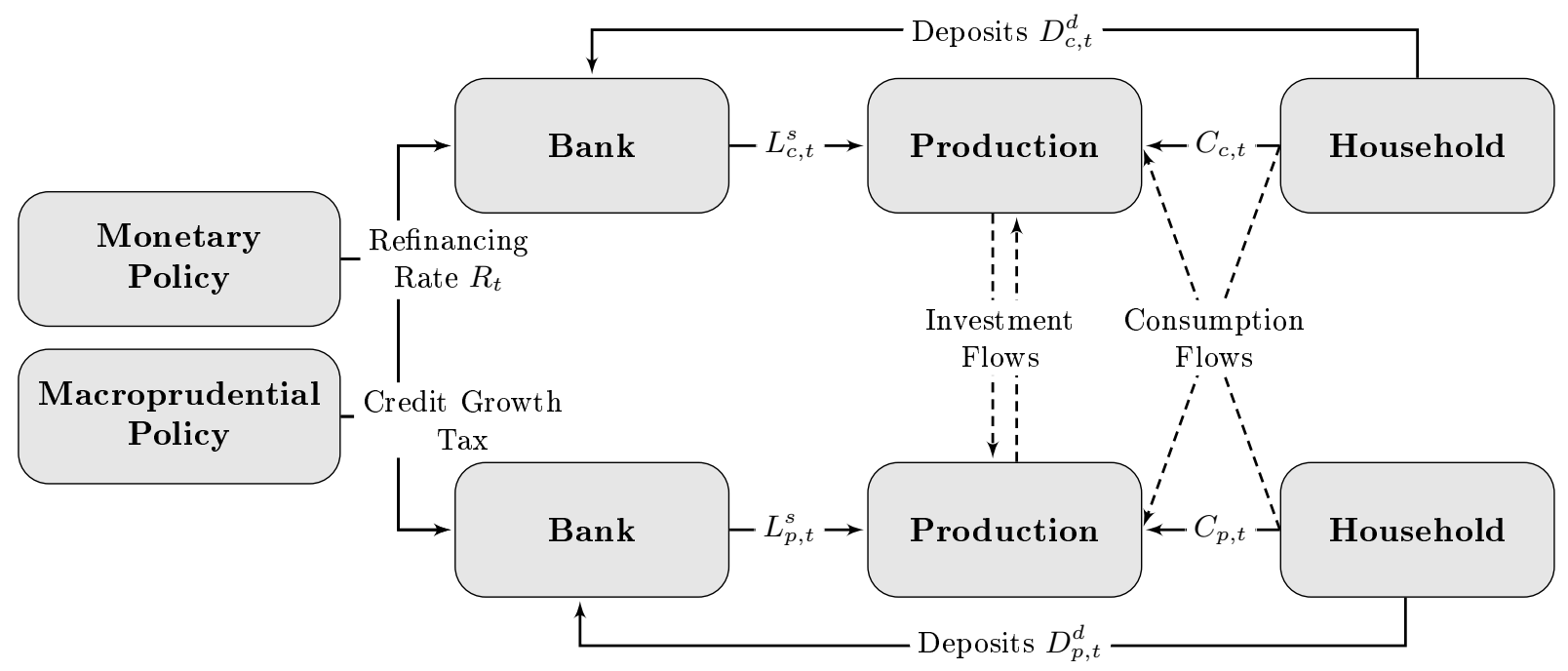

Figure 1: The model of a two-country monetary union 
This section describes the private sector of the economy, by distinguishing the standard components of the DSGE setting (consumers and firms) from the financial component of the analysis (entrepreneurs, banks and capital suppliers). ${ }^{2}$

\subsection{The standard part of the model}

\section{Households}

The representative household maximizes his utility intertemporally subject to a budget constraint. The welfare index $\mathcal{W}_{i, t}$ reads as: $\sum_{\tau=0}^{\infty} \beta^{\tau} \exp \left(\varepsilon_{i, t+\tau}^{U}\right) \mathcal{U}\left(C_{i, t+\tau}, H_{i, t+\tau}\right)$. Here, $C_{i, t}$ is the consumption, $H_{i, t}$ is labor effort, $\beta \in(0,1)$ is the subjective discount factor and $\varepsilon_{i, t}^{U}$ is an exogenous shock to time-preferences. The period utility function takes the form:

$$
\mathcal{U}\left(C_{i, t}, H_{i, t}\right) \equiv \frac{1}{\left(1-\sigma_{i}^{C}\right)}\left(C_{i, t}-h_{i}^{C} C_{i, t-1}\right)^{1-\sigma_{i}^{C}}-\frac{\chi_{i}}{\left(1+\sigma_{i}^{H}\right)} H_{i, t}^{1+\sigma_{i}^{H}},
$$

where $\sigma_{i}^{H} \geq 0$ is the curvature coefficient in the disutility of labor, $\sigma_{i}^{C} \geq 0$ is the risk aversion coefficient and $h_{i}^{C} \in[0 ; 1)$ are external consumption habits. The budget constraint reads as, $W_{i, t} H_{i, t}+\left(1+R_{i, t-1}^{D}\right) D_{i, t}^{d}+\Pi_{i, t}=P_{i, t}^{C} C_{i, t}+D_{i, t+1}^{d}+T_{i, t}+P_{i, t} A C_{i, t}^{D}$. The income of the representative household is made of labor income (with nominal wage, $W_{i, t}$ ), interest payments for deposits (where $D_{i, t}^{d}$ stands for deposits subscribed in period $t-1$ and $1+R_{i, t-1}^{D}$ is the gross nominal rate of interest between period $t-1$ an period $t$ ), and earnings $\Pi_{i, t}$ from shareholdings of intermediate firms. The representative household spends this income on consumption, deposits and tax payments (for a nominal amount of $T_{i, t}$ ). In addition to close the model, we assume that the household has to pay quadratic adjustment costs $A C_{i, t}^{D}(j)$ to buy new deposit services and holds a constant real quantity of money balances $\bar{M}_{i}$.

\section{Firms}

There is a continuum of monopolistically competitive firms, each producing differentiated goods using hours of work $H_{i, t}$ and capital inputs $K_{i, t}$ and set production prices $P_{i, t}$ according to the Calvo model. Output supplied by firms is $Y_{i, t}=\exp \left(\varepsilon_{i, t}^{A}\right) K_{i, t}^{\alpha} H_{i, t}^{1-\alpha}$ where $\varepsilon_{i, t}^{A}$ is an innovation to the productivity and $\alpha \in[0,1]$ is the share of capital services in the production. According to the Calvo mechanism, each period firms are not allowed to re-optimize the selling price with probability $\theta_{i}^{P}$ but price increases of $\xi_{i}^{P} \in[0,1]$ at last period's rate of price inflation, $P_{i, t}=\pi_{i, t-1}^{\xi_{i}^{P}} P_{i, t-1}$ where $\pi_{i, t}=P_{i, t} / P_{i, t-1}$. Under this setting, it is possible to derive the aggregate inflation rate of production goods, it is defined by the function, $\pi_{i, t}=f\left(\mathbb{E}_{t} \pi_{i, t+1}, \pi_{i, t-1}, M C_{i, t}\right)$ where $M C_{i, t}$ is the marginal cost of production.

\footnotetext{
${ }^{2} \mathrm{~A}$ detailed presentation of the framework is provided in appendix.
} 


\subsection{Financial frictions}

In this setting, financial frictions occur because investment in new capital assets should be financed. The return of investment projects financed by entrepreneurs is heterogeneous and leads entrepreneurs to default on their loans when the return of capital is set too low compared to the cost of credit. In what follows, we present in some details the problem faced by the entrepreneur (that takes the decision to finance new investments) and sketch the programs of the banking sector and the capital suppliers.

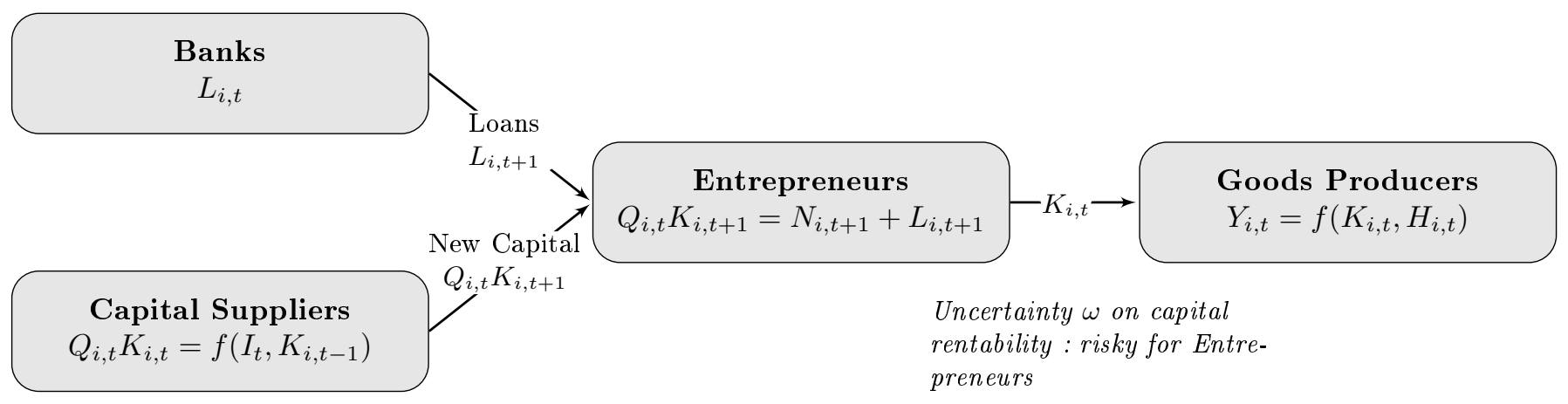

Figure 2: Financial frictions through the introduction of an entrepreneur which finances capital services using its net wealth and industrial loans

Figure 2 depicts the relations between financial intermediaries, entrepreneurs and firms. As the entrepreneur is at the center of the analysis, we first single out the decisions of this agent, then we provide a compact presentation of capital suppliers and of financial intermediaries. ${ }^{3}$

\section{Entrepreneurs}

In each economy, the representative entrepreneur $i$ finances the capital renting of intermediate firms. Each intermediate firm and entrepreneur belong to the same business $i$. In period $t$, entrepreneur $i$ conducts a great number of heterogeneous projects with total value $Q_{i, t} K_{i, t+1}(i)$, where $Q_{i, t}$ is the price of capital and $K_{i, t+1}(i)$ is the amount of capital financed. These projects are financed by his net wealth and by loans from the banking system $\left(L_{i, t+1}^{d}(i)\right)$. The balance sheet of the representative entrepreneur is determined by:

$$
Q_{i, t} K_{i, t+1}(i)-N_{i, t+1}(i)=L_{i, t+1}^{\mathcal{H}}(i)
$$

where $L_{i, t+1}^{\mathcal{H}}(i)=L_{i, t+1}^{d}(i)-h_{i}^{L}\left(L_{i, t}^{d}-L_{i}^{d}\right)$ denotes external demand habits for loans. ${ }^{4}$ The investment projects undertaken by the entrepreneur are risky and differ with respect to their individual returns and allow entrepreneurs to default on its loans

\footnotetext{
${ }^{3}$ More details are provided in appendix.

${ }^{4}$ These lending demand habits are deemed necessary to replicate the dynamic of loans. In the estimation exercise, we use the total stock of loans, they are of different maturities implying a strong autocorrelation. Simply by introducing loan demand habits, taking into account the high autocorrelation of loans becomes tractable easily and does not change the steady state of the model.
} 
for its least profitable projects. To model individual riskiness, we assume that each project has an individual return equal to $\omega\left(1+R_{i, t}^{k}\right)$, i.e. that the aggregate return of investment projects in the economy $1+R_{i, t}^{k}$ is multiplied by a random value $\omega$ (drawn from a Pareto distribution). ${ }^{5}$ Defining the value for a profitable project by $\bar{\omega}_{i, t}=$ $E\left(\omega \mid \omega \geq \omega_{i, t}^{C}\right)$ (where $\omega_{i, t}^{C}$ is the critical value of $\omega$ that distinguishes profitable and non-profitable projects), the profit function of entrepreneur $i$ after aggregating all projects becomes:

$\Pi_{i, t}^{E}(i)=\left\{\begin{array}{r}\bar{\omega}_{i, t+1}\left(1+R_{i, t+1}^{k}\right) Q_{i, t} K_{i, t+1}(i)-\left(1+R_{i, t}^{L}\right) \\ L_{i, t+1}^{\mathcal{H}}(i) \text { with probability } \eta_{i, t+1}^{E}, . \\ 0 \text { with probability } 1-\eta_{i, t+1}^{E}\end{array}\right.$.

where $\eta_{i, t+1}^{E}$ is the time-varying expected share of profitable projects. Since entrepreneurs cannot screen the value of $\bar{\omega}_{i, t+1}$ ex ante, $\omega_{i, t}^{C}$ cannot be a control variable of the financial contract between borrowers and lenders contrary to Bernanke et al. (1999). To introduce a financial accelerator mechanism, we borrow a concept of De Grauwe (2010) applied in a different context, by assuming that entrepreneurs' forecasts regarding the aggregate profitability of a given project $\bar{\omega}_{i, t}$ are optimistic (i.e., biased upwards). ${ }^{6}$ The perceived ex ante value of profitable projects is defined by the CES function:

$$
g\left(\bar{\omega}_{i, t+1}, \varepsilon_{i, t}^{Q}\right)=\gamma_{i}\left(\bar{\omega}_{i, t+1}\right)^{\frac{\varkappa_{i}}{\left(\varkappa_{i}-1\right)}}\left(e^{\varepsilon_{i, t}^{Q}}\right)^{\frac{1}{\left(\varkappa_{i}-1\right)}},
$$

where $\varepsilon_{i, t}^{Q}$ is an $A R(1)$ process, ${ }^{7} \varkappa_{i}$ is the elasticity of the external finance premium and $\gamma_{i}$ is a scale parameter. ${ }^{8}$ In this expression, the exogenous shock is affected by exponent $1 /\left(\varkappa_{i}-1\right)$ to normalize to unity the impact of the financial shock $\varepsilon_{i, t}^{Q}$ in the $\log$ deviation form of the model. Thus, ex-ante the entrepreneur chooses a capital amount $K_{i, t+1}(i)$ that maximizes its expected profit defined as:

$$
\max _{\left\{K_{i, t+1}(i)\right\}} \mathbb{E}_{t}\left\{\eta_{i, t+1}^{E}\left[g\left(\bar{\omega}_{i, t+1}, \varepsilon_{i, t}^{Q}\right)\left(1+R_{i, t+1}^{k}\right) Q_{i, t} K_{i, t+1}(i)-\left(1+R_{i, t}^{L}\right) L_{i, t+1}^{\mathcal{H}}(i)\right]\right\} .
$$

Using the characteristics of the Pareto distribution, the expected spread required by representative entrepreneur $e$ to undertake the decision to finance firms' investment

\footnotetext{
${ }^{5}$ With respect to the standard framework standardly used in the literature (Bernanke et al., 1999), we assume that the heterogeneity in the return of investment project undertaken by firms is modeled using a Pareto distribution as in Poutineau and Vermandel (2015a,b). This device commonly used in other branches of the economic literature provides a series of interesting features in the analysis and allows an easier estimation of the financial amplification effect.

${ }^{6}$ Assuming optimistic firms is motivated empirally, Bachmann and Elstner (2013) find evidence of such expectations for German firms using microdata. This hypothesis of the expectations of the private sector is very close to the utility functions introduced by Goodhart et al. (2005) for bankers. In our setting, the financial accelerator does not result from a moral hazard problem but rather from a bias in the expectations of the private sector.

${ }^{7}$ This shock affects the expected profitability of financial projects by rising in exogeneously the risk premium implying an increase in the cost of capital and hence a reduction in investment as underlined by Gilchrist et al. (2009b) for the US economy.

${ }^{8}$ This parameter is needed to make the steady state independent of $\varkappa_{i}$, such that $\gamma_{i}=\bar{\omega}^{1 /\left(1-\varkappa_{i}\right)}$.
} 
is:

$$
S_{i, t}(i)=\frac{\mathbb{E}_{t}\left(1+R_{i, t+1}^{k}\right)}{1+R_{i, t}^{L}}=\gamma_{i}^{\varkappa_{i}-1}\left[\frac{\kappa}{\kappa-1}\left(1-\frac{N_{i, t+1}(i)}{Q_{i, t} K_{i, t+1}(i)}\right)\right]^{\varkappa_{i}} e^{\varepsilon_{i, t}^{Q}} .
$$

The size of the accelerator is determined by the elasticity of the external finance premium $\varkappa_{i}$. For $\varkappa_{i}>0$, the external finance premium is a positive function of the leverage ratio, $Q_{i, t} K_{i, t+1}(i) / N_{i, t+1}(i)$, so that an increase in net wealth induces a reduction of the external finance premium. This phenomenon disappears if $\varkappa_{i}=0$. Concerning the exogenous movements of the external finance premium, a positive realization of $\varepsilon_{i, t}^{Q}$ means that entrepreneurs require a higher expected profitability of capital $E_{t} R_{i, t+1}^{k}$ to finance investment for a given level of lending conditions $R_{i, t}^{L}$. Furthermore, a shock that hits the entrepreneur net wealth $N_{i, t+1}(i)$ will also affect the return of physical capital in the economy. As the rentability of capital is a cost for the intermediate sector, a variation in the net wealth will have aggregate consequences on goods supply through the channel of the capital market as underlined by Gilchrist et al. (2009b). Thus the net wealth of the entrepreneur in the next period is equal to:

$$
N_{i, t+1}(i)=\left(1-\tau_{i}^{E}\right) \frac{\Pi_{i, t}^{E}(i)}{e^{\varepsilon_{i, t}^{N}}}
$$

where $\varepsilon_{i, t}^{N}$ is an exogenous process of net wealth destruction and $\tau_{i}^{E}$ is a proportional tax on the profits.

\section{Banks}

The representative bank operates in a regime of monopolistic competition to provide deposit and credit services to households and firms. Each period, the bank collects deposits $D_{i, t}$ from households remunerated at a rate $R_{i, t}^{D}(b)$, borrows funds $L_{i, t}^{R F}$ for a refinancing rate $R_{t}$ from the central bank, and supplies loans $L_{i, t}^{s}$ to entrepreneurs whose rate is $R_{i, t}^{L}(b)$. Given the biased expectations of entrepreneurs, banks are not able to distinguish between solvable and defaulting projects, in turn they face a credit risk modelled by $1-\eta_{i, t+1}^{E}$ which is the expected rate of default of entrepreneurs. Allowing bank to size back their loans in case of default, they must pay a proportional audition $\operatorname{cost} \mu^{B} \in[0,1]$ which can also be interpreted as the loss-given-default. Its expected one-period profits can be expressed as:

$$
\begin{aligned}
\mathbb{E}_{t} \Pi_{i, t+1}^{B}(b) & =\underbrace{\left[\mathbb{E}_{t} \eta_{i, t+1}^{E}+\left(1-\mu^{B}\right)\left(1-\eta_{i, t+1}^{E}\right)\right]}_{\text {credit default }} \underbrace{\left(1+R_{i, t}^{L}(b)\right) L_{i, t+1}^{s}(b)}_{\text {Loan supply revenues }} \\
& -\underbrace{\left(1+R_{t}\right) L_{i, t+1}^{R F}(b)}_{\text {ECB refinancing cost }}-\underbrace{\left(1+R_{i, t}^{D}\right) D_{i, t+1}(b)}_{\text {Deposit cost }},
\end{aligned}
$$

which has to be optimized under the balance sheet constraint:

$$
L_{i, t+1}^{s}(b)=D_{i, t+1}(b)+L_{i, t+1}^{R F}(b)+B K_{i, t+1}(b),
$$

where $B K_{i, t+1}$ is the amount of equity hold by the bank. 
One of the key equations of the paper that will be affected by macroprudential policy is the first order condition on commercial loans:

$$
1+M C_{i, t}^{L}=\frac{\left(1+R_{t}\right)}{\left[1-\mu^{B}\left(1-\mathbb{E}_{t} \eta_{i, t+1}^{E}\right)\right]} .
$$

Following Darracq-Pariès et al. (2011), we measure the pass-through of interest rates by supposing that the representative bank sets the deposit and credit rates in staggered basis à la Calvo. Letting $\theta_{i}^{L}\left(\theta_{i}^{D}\right)$ denotes the country specific probability of the bank not being able to reset it credit (deposit) interest rate. The aggregate deposit rate reads as, $R_{i, t}^{D}=f\left(\mathbb{E}_{t} R_{i, t+1}^{D}, R_{t}, \varepsilon_{i, t}^{D}\right)$ where $\varepsilon_{i, t}^{D}$ is a markup shock and $R_{t}$ is the ECB refinancing rate. Similarly, the aggregate credit rate is defined by, $R_{i, t}^{L}=$ $f\left(\mathbb{E}_{t} R_{i, t+1}^{L}, M C_{i, t}^{L}\right)$. Solving forward $R_{i, t}^{L}$, one can see that current and expected future ECB rate $R_{t}$ and firms' profitability $\mathbb{E}_{t} \eta_{i, t+1}^{E}$ drive today's credit rates.

\section{Capital Suppliers}

The representative capital producer buys depreciated capital stock $(1-\delta) K_{i, t}$ and investment goods $I_{i, t}$ and produces new capital goods $K_{i, t+1}$ at a price $Q_{i, t}$. Capital supplier buys home and foreign investment goods, $I_{i, t}=\left(\left(1-\alpha_{i}^{I}\right)^{1 / \mu} I_{h i, t}^{(\mu-1) / \mu}+\right.$ $\left.\left(\alpha_{i}^{I}\right)^{1 / \mu} I_{f i, t}^{(\mu-1) / \mu}\right)^{\mu /(\mu-1)}$ where $1-\alpha_{i}^{I}>0.5$ is the home bias in its consumption basket.

\section{Policies and general equilibrium}

This section describes the rest of the model, namely the behavior of authorities and the general equilibrium conditions of the model.

\subsection{Policies}

As depicted in Figure 1, the conduct of macroeconomic policy is shared between a common central bank and regional macroprudential authorities.

\section{Monetary Policy}

The central bank of the monetary union follows an interest rate rule defined by:

$$
\left(\frac{1+R_{t}}{1+\bar{R}}\right)=\left(\frac{1+R_{t-1}}{1+\bar{R}}\right)^{\rho}\left(\left(\pi_{t}^{C}\right)^{\phi^{\pi}}\left(\frac{Y_{t}}{Y_{t-1}}\right)^{\phi^{\Delta y}}\right)^{(1-\rho)} e^{\varepsilon_{t}^{R}},
$$

where $R_{t}$ is the interest rate set by the central bank and $\bar{R}$ its steady state, $\rho$ is the interest rate smoothing coefficient, $\varepsilon_{t}^{R}$ is an exogenous $\operatorname{AR}(1)$ monetary policy shock common to the monetary union members, $\phi^{\pi}$ is the level of reaction to inflation, $\phi^{\Delta y}$ 
is the GDP growth target. In this expression, union-wide inflation and GDP growth are defined by a geometric average that account for the relative size of each country, $\pi_{t}^{C}=\left(\pi_{c, t}^{C}\right)^{n}\left(\pi_{p, t}^{C}\right)^{1-n}$ and $Y_{t}=\left(Y_{c, t}\right)^{n}\left(Y_{p, t}\right)^{1-n}$. In this paper we assume that the central bank follows an optimal monetary policy, so the parameters of the Taylor rule are chosen to maximize a second order approximation of household utility function combined with the equilibrium conditions of the model.

\section{Macroprudential Policy}

Following Quint and Rabanal (2014), the macroprudential instrument $\left(\mathcal{M} \mathcal{P}_{i, t}\right)$ reacts to credit growth $\left(L_{i, t}^{s} / L_{i, t-1}^{s}\right)$. A tightening of credit conditions due to macroprudential measures increases the interest rate faced by borrowers by modifying the marginal cost of loan production $\left(M C_{i, t}^{L}\right)$. This macroprudential tool affects the credit market conditions countercyclically to dampen credit cycles and provides macroeconomic stabilization.

The general expression of the transmission channel can be understood simply by taking into account that in our setting the interest rate on loans is determined by a new Keynesian interest rate Phillips curve such that $R_{i, t}^{L}=f\left(\mathbb{E}_{t} R_{i, t+1}^{L}, M C_{i, t}^{L}\right)$, where the current marginal cost of loan production given in Equation 9 is directly affected by the macroprudential instrument $\mathcal{M} \mathcal{P}_{i, t}$ with a policy stance $\phi_{i} \geq 0$ :

$$
1+M C_{i, t}^{L}=\frac{\left(1+R_{t}\right)\left(\mathcal{M} \mathcal{P}_{i, t}\right)^{\phi_{i}}}{\left[1-\mu^{B}\left(1-\mathbb{E}_{t} \eta_{i, t+1}^{E}\right)\right]} .
$$

The macroprudential instrument $\mathcal{M P}_{i, t}$ is introduced in an ad-hoc fashion to affect directly the cost of loan production (and thus their interest rate, $R_{i, t}^{L}$ ) through a tax on refinancing from the central bank. The main difference between monetary and macroprudential policy concerns the scope of their respective tools. As a main difference with monetary policy, macroprudential policy does not affect the deposit rate (and in turn households' consumption) and allows to target directly the origin of the financial imbalances. A macroprudential tightening here can be interpreted as an internalization of the cost of over-borrowing from entrepreneurs because of their biased expectations through a Pigouvian taxation as in Jeanne and Korinek (2010). Extra-earnings generated by the taxation are kept by banks and accumulated in terms of bank capital which enhances the resilience of the financial system. ${ }^{9}$ In addition, the use of a country-adjusted macroprudential policy introduces more granularity that a single monetary policy cannot offer for an heterogeneous monetary union such as the Euro area.

Assuming that macroprudential actions are based upon the growth of loans, we distinguish two possible schemes that can be either regional or union-wide:

$$
\mathcal{M P} \mathcal{P}_{i, t}=L_{i, t}^{s} / L_{i, t-1}^{s} \quad \text { or } \quad \mathcal{M P} t=\left(L_{c, t}^{s} / L_{c, t-1}^{s}\right)^{n}\left(L_{p, t}^{s} / L_{p, t-1}^{s}\right)^{1-n}
$$

\footnotetext{
${ }^{9}$ We focus on welfare-enhancing macroprudential policies directed toward borrowers. The stability of lenders assessed by the bank capital, which is another key facet of macroprudential policy, is not in the scope of the paper.
} 


\begin{tabular}{c|c|c|c}
\hline \hline Scenario & Targeting rule & Policy stance & Policy Channel \\
\hline$(1)$ & $\mathcal{M} \mathcal{P}_{t}=\left(L_{c, t}^{s} / L_{c, t-1}^{s}\right)^{n}\left(L_{p, t}^{s} / L_{p, t-1}^{s}\right)^{1-n}$ & $\phi_{c}=\phi_{p}=\phi$ & $1+M C_{i, t}^{L}=\frac{\left(1+R_{t}\right)\left(\mathcal{M} \mathcal{P}_{t}\right)^{\phi}}{\left[1-\mu^{B}\left(1-\mathbb{E}_{t} \eta_{i, t+1}^{E}\right)\right]}$ \\
$(2)$ & $\mathcal{M} \mathcal{P}_{t}=\left(L_{c, t}^{s} / L_{c, t-1}^{s}\right)^{n}\left(L_{p, t}^{s} / L_{p, t-1}^{s}\right)^{1-n}$ & $\phi_{c} \neq \phi_{p}$ & $1+M C_{i, t}^{L}=\frac{\left(1+R_{t}\right)\left(\mathcal{M} \mathcal{P}_{t}\right)_{i}}{\left[1-\mu^{B}\left(1-\mathbb{E}_{t} \eta_{i, t+1}^{E}\right)\right]}$ \\
$(3)$ & $\mathcal{M} \mathcal{P}_{i, t}=\left(L_{i, t}^{s} / L_{i, t-1}^{s}\right)$ for $i \in\{h, f\}$ & $\phi_{c}=\phi_{p}=\phi$ & $1+M C_{i, t}^{L}=\frac{\left(1+R_{t}\right)\left(\mathcal{M} \mathcal{P}_{i, t}\right)^{\phi}}{\left[1-\mu^{B}\left(1-\mathbb{E}_{t} \eta_{i, t+1}\right)\right]}$ \\
$(4)$ & $\mathcal{M P}_{i, t}=\left(L_{i, t}^{s} / L_{i, t-1}^{s}\right)$ for $i \in\{h, f\}$ & $\phi_{c} \neq \phi_{p}$ & $1+M C_{i, t}^{L}=\frac{\left(1+R_{t}\right)\left(\mathcal{M} \mathcal{P}_{i, t}\right)_{i}^{\phi_{i}}}{\left[1-\mu^{B}\left(1-\mathbb{E}_{t} \eta_{i, t+1}^{E}\right)\right]}$ \\
\hline \hline
\end{tabular}

Table 1: Different levels of implementation of Macroprudential policy

In addition, we also analyze the possibility for the policy stance $\phi_{i}$ to be homogeneously or heterogeneously between the two areas of the monetary union. Table 1 summarizes all the possible scenarios that our setup offers: we contrast four situations combining regional $\left(\mathcal{M P} \mathcal{P}_{i, t}\right.$ with $\left.i \in\{c, p\}\right)$ or union-wide $\left(\mathcal{M P} \mathcal{P}_{t}\right)$ loan developments with either an uniform $\left(\phi_{c}=\phi_{p}\right)$ or regional $\left(\phi_{c} \neq \phi_{p}\right)$ setting of the macroprudential reactivity parameter.

In Table 1, situation (1) assumes a uniform reaction of macroprudential policy to global lending developments in the Eurozone, while at the other extreme, scenario (4) assumes a granular policy combining a regional definition of both the reaction variable and policy stance. Scenarios (2) and (3) are intermediate solutions. Policy stance parameters are chosen to maximize the joint welfare of countries belonging to the monetary union. As policy evaluation is based on the optimal decisions of authorities, the value of parameters $\phi_{i}$ will be set by optimizing households' welfare index:

$$
\max _{\Omega} n \mathcal{W}_{c, t}+(1-n) \mathcal{W}_{p, t}
$$

where $\Omega$ is the set of policy parameters to be optimally chosen. We employ perturbation methods taking a second order approximation to the full model which provides an accurate evaluation of the welfare criterion to rank and compare different policies.

\subsection{Aggregation and general equilibrium}

The general equilibrium of the model is obtained after $(i)$ aggregating all agents and varieties in the economy, (ii) imposing market clearing for all markets, and (iii) substituting the relevant demand functions. In this model, there are 7 country specific structural shocks for $i \in\{h, f\}$ and one common shock in the Taylor rule. For $s=\{U, A, I, Q, N, D\}$, the shocks follow a first order autoregressive process such that $\varepsilon_{i, t}^{s}=\rho_{i}^{s} \varepsilon_{i, t-1}^{s}+\eta_{i, t}^{s}$ while for exogenous spending the process reads as follows: $\varepsilon_{i, t}^{G}=\rho_{i}^{G} \varepsilon_{i, t-1}^{G}+\eta_{i, t}^{G}+\rho^{a g} \eta_{i, t}^{A}$. In these first-order autoregressive process, $\rho_{i}^{U}, \rho_{i}^{A}, \rho_{i}^{G}$, $\rho_{i}^{I}, \rho_{i}^{Q}, \rho_{i}^{N}, \rho_{i}^{D}$ and $\rho^{R}$ are autoregressive roots of the exogenous variables. $\eta_{i, t}^{U}, \eta_{i, t}^{A}$, $\eta_{i, t}^{G}, \eta_{i, t}^{I}, \eta_{i, t}^{Q}, \eta_{i, t}^{N}, \eta_{i, t}^{D}$ and $\eta_{t}^{R}$ are standard errors that are mutually independent, serially uncorrelated and normally distributed with zero mean and variances $\sigma_{i, U^{\prime}}^{2} \sigma_{i, A^{\prime}}^{2}$, $\sigma_{i, G^{\prime}}^{2} \sigma_{i, I}^{2}, \sigma_{i, Q^{\prime}}^{2}, \sigma_{i, N}^{2}, \sigma_{i, D}^{2}$ and $\sigma_{R}^{2}$ respectively. A general equilibrium is defined as a sequence of quantities $\left\{\mathcal{Q}_{t}\right\}_{t=0}^{\infty}$ and prices $\left\{\mathcal{P}_{t}\right\}_{t=0}^{\infty}$ such that for a given sequence of 
quantities $\left\{\mathcal{Q}_{t}\right\}_{t=0}^{\infty}$ and the realization of shocks $\left\{\mathcal{S}_{t}\right\}_{t=0}^{\infty}$, the sequence $\left\{\mathcal{P}_{t}\right\}_{t=0}^{\infty}$ guarantees the equilibrium on the capital, labor, loan, intermediate goods and final goods markets..

On the goods Market, the aggregate price index of the national goods evolves according to:

$$
P_{i, t}^{1-\epsilon_{P}}=\theta_{i}^{P}\left[P_{i, t-1}\left(\frac{P_{i, t-1}}{P_{i, t-2}}\right)^{\xi_{i}^{P}}\right]^{1-\epsilon_{P}}+\left(1-\theta_{i}^{P}\right)\left(P_{i, t}^{*}\right)^{1-\epsilon_{P}} .
$$

The equilibrium condition on the final goods market is defined by the aggregation of the demand function from final goods producers, $\mathcal{G}\left(Y_{i, t}(i)\right)=Y_{i, t}^{d} \mathcal{G}\left(P_{i, t}(i) / P_{i, t}\right)^{-\epsilon_{P}}$ where $\mathcal{G}\left(Y_{i, t}(i)\right)=\exp \left(\varepsilon_{i, t}^{A}\right) \mathcal{G}\left(K_{i, t}(i)^{\alpha} H_{i, t}^{d}(i)^{1-\alpha}\right)$ is the aggregation of intermediate goods suppliers and $Y_{i, t}^{d}$ is the resources constraint. Thus, replacing the demand functions of foreign and home goods (consumption and investment), we finally obtain the home final goods market equilibrium in the home country:

$$
\begin{aligned}
\frac{Y_{c, t}}{\Delta_{c, t}^{P}} & =\left(1-\alpha_{c}^{C}\right)\left(\frac{P_{c, t}}{P_{c, t}^{C}}\right)^{-\mu} C_{c, t}+\left(1-\alpha_{c}^{I}\right)\left(\frac{P_{c, t}}{P_{c, t}^{I}}\right)^{-\mu}\left(1+A C_{c, t}^{I}\right) I_{c, t} \\
& +\frac{n-1}{n}\left(\alpha_{p}^{C}\left(\frac{P_{c, t}}{P_{p, t}^{C}}\right)^{-\mu} C_{p, t}+\alpha_{p}^{I}\left(\frac{P_{c, t}}{P_{p, t}^{I}}\right)^{-\mu}\left(1+A C_{p, t}^{I}\right) I_{p, t}\right) \\
& +G_{c, t}+A C_{c, t}^{D}
\end{aligned}
$$

where $\Delta_{i, t}^{P}=\mathcal{G}\left(P_{i, t}(i) / P_{i, t}\right)^{-\epsilon_{P}}$ denotes the price dispersion term, which is induced by the assumed nature of price stickiness, is inefficient and entails output loss. To close the model, adjustment costs on deposits are entirely home biased: $A C_{i, t}^{D}=$ $\mathcal{G}\left(A C_{i, t}^{D}(i)^{\left(\epsilon_{P}-1\right) / \epsilon_{P}}\right)^{\epsilon_{P} /\left(\epsilon_{P}-1\right)}$, the associated demand function is, $A C_{i, t}^{D}(i)=\left(P_{i, t}(i) / P_{i, t}\right)^{-\epsilon_{P}} A C_{i, t}^{D}$.

Concerning the equilibrium on the loan market, it is defined by the aggregate demand function from retail banks: $\mathcal{G}\left(L_{i, t+1}^{s}(b)\right)=\Delta_{i, t}^{L} L_{i, t+1}^{d}$, where $\Delta_{i, t}^{L}=\mathcal{G}\left(R_{i, t}^{L}(b) / R_{i, t}^{L}\right)^{-\epsilon_{L}}$ is the credit rate dispersion term and $L_{i, t+1}^{d}$ is the aggregate demand. The aggregate loan rate index evolves according to:

$$
\left(R_{i, t}^{L}\right)^{1-\epsilon_{L}}=\theta_{i}^{L}\left(R_{i, t-1}^{L}\right)^{1-\epsilon_{L}}+\left(1-\theta_{i}^{L}\right)\left(R_{i, t}^{L}\right)^{1-\epsilon_{L}} .
$$

Eventually the equilibrium on the deposit market is defined by the aggregate demand for deposit services of households and the aggregate supply from deposit packers. Aggregating the demand function from deposit packers leads to the equilibrium on this market: $\mathcal{G}\left(D_{i, t+1}(b)\right)=\Delta_{i, t}^{D} \mathcal{G}\left(D_{i, t+1}^{d}(j)\right)$, where $\Delta_{i, t}^{D}=\mathcal{G}\left(\left(R_{i, t}^{D}(b) / R_{i, t}^{D}\right)^{-\mu_{i, t}^{D} /\left(\mu_{i, t}^{D}-1\right)}\right.$ is the interest rate dispersion term, while the aggregate deposit rate index evolves according to:

$$
\left(R_{i, t}^{D}\right)^{\frac{1}{1-\mu_{i, t}^{D}}}=\theta_{i}^{D}\left(R_{i, t-1}^{D}\right)^{\frac{1}{1-\mu_{i, t}^{D}}}+\left(1-\theta_{i}^{D}\right)\left(R_{i, t}^{D}\right)^{\frac{1}{1-\mu_{i, t}^{D}}}
$$




\section{Estimation}

\subsection{Data}

We split the Eurozone in two groups: core and periphery. Since EMU creation, countries with current account surpluses belong to the core country group, other countries belong to the peripheral group. In our sample, the core country group is made of Austria, Belgium, Germany, Finland, France, Luxembourg and the Netherlands, while the peripheral group comprises Spain, Greece, Ireland, Italy and Portugal. France is halfway since its current account had been positive from 1999 to 2003 and we make the hypothesis that France is still a core country despite its recent current account deficits. ${ }^{10}$

The model is estimated with Bayesian methods on Eurozone quarterly data over the sample period 1999Q1 to 2013Q3, which makes 59 quarterly observations for each variable (except for financial variables). The dataset includes 15 times series: real GDP (Eurostat), real consumption (Eurostat), real investment (Eurostat), the ECB refinancing operation rate (Eurostat, one year maturity), the HICP (ECB, overall index, deseasonalized using a multiplicative decomposition), the overnight deposit rate of households and firms (ECB), the outstanding amount of loan and lending rate to non-financial corporations (ECB, 2003-2013, deseasonalized using a multiplicative decomposition). Data with a trend are made stationary using a linear trend and are divided by the population. We also demean the data because we do not use the information contained in the observable mean. Figure 3 plots the transformed data. ${ }^{11}$
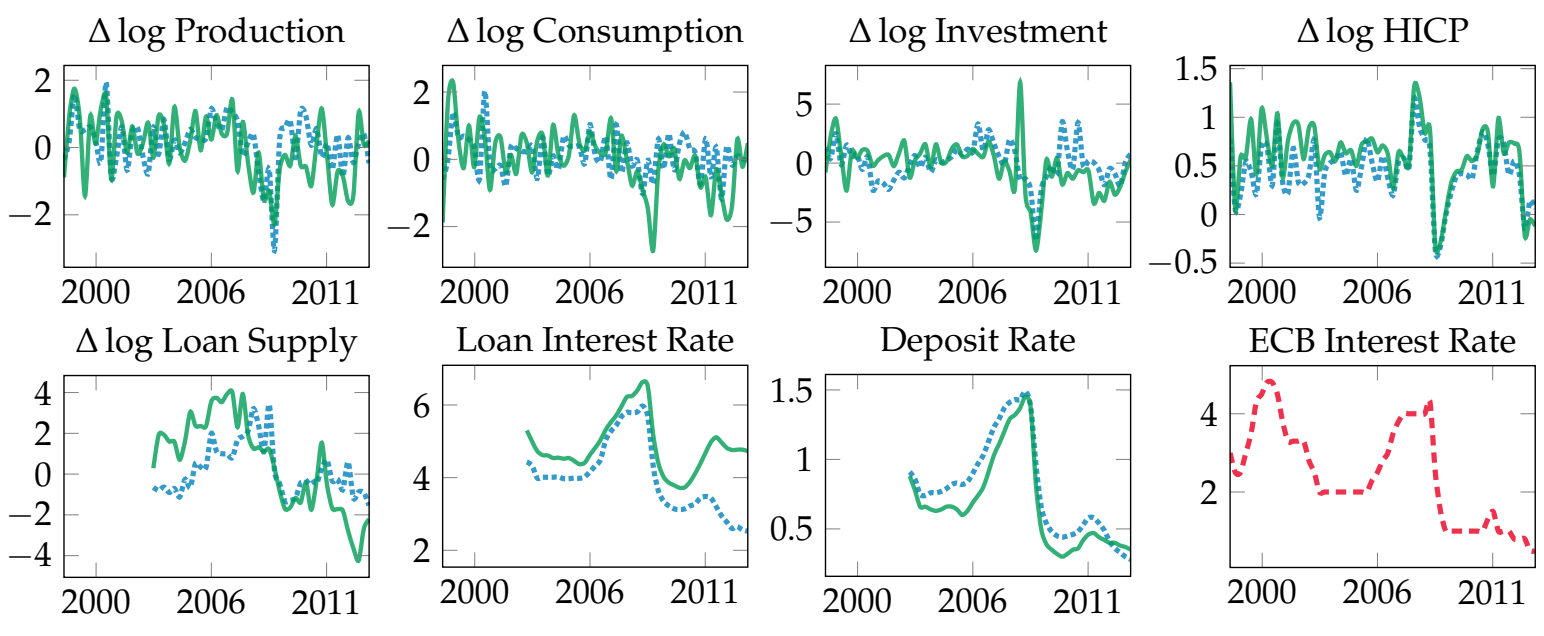

Core countries

Peripheral countries

Euro Area

Figure 3: Observable variables

The methodology is standard to the Bayesian estimations of DSGE models. Interest rates data are annualized, we take into account this maturity by multiplying

\footnotetext{
${ }^{10}$ Quint and Rabanal (2014) use the same assumption, there are reasons that justify this choice. The French government bond yield remains at very low levels, house prices and the credit-minusrefinancing spread for firms remained quite stable during the financial crisis episode.

${ }^{11}$ Data related to loan supply and credit rates are missing between 1999 and 2003 as the ECB does not provide backdated series before 2003 for these series.
} 
by 4 the rates in the measurement equation. The number of shocks and observable variables are the same to avoid stochastic singularity issue. Recalling that $i \in\{c, p\}$, the vectors of observables:

$$
\mathcal{Y}_{t}^{o b s}=\left[\Delta \log \hat{Y}_{i, t}, \Delta \log \hat{C}_{i, t}, \Delta \log \hat{I}_{i, t}, r_{t}, \pi_{i, t}^{c}, \Delta \log \hat{L}_{i, t}^{s}, r_{i, t}^{L}, r_{i, t}^{D}\right]^{\prime},
$$

and measurement equations:

$$
\mathcal{Y}_{t}=\left[\hat{y}_{i, t}-\hat{y}_{i, t-1}, \hat{c}_{i, t}-\hat{c}_{i, t-1}, \hat{\imath}_{i, t}-\hat{\imath}_{i, t-1}, 4 \hat{r}_{t}, \hat{\pi}_{i, t}^{c}, \hat{l}_{i, t}^{s}-\hat{l}_{i, t-1}^{s}, 4 \hat{r}_{i, t}^{L}, 4 \hat{r}_{i, t}^{D}\right]^{\prime}
$$

where $\Delta$ denotes the temporal difference operator, $\hat{X}_{t}$ is per capita variable of $X_{t}$ and $\hat{x}_{t}$ is the loglinearized version of $X_{t}$. The model matches the data setting:

$$
\mathcal{Y}_{t}^{o b s}=\overline{\mathcal{Y}}+\mathcal{Y}_{t}
$$

where $\overline{\mathcal{Y}}$ is the vector of the mean parameters, we suppose this is a vector of all 0 . The posterior distribution combines the likelihood function with prior information. To calculate the posterior distribution to evaluate the marginal likelihood of the model, the Metropolis-Hastings algorithm is employed. We compute the posterior moments of the parameters using a sufficiently large number of draws, having made sure that the MCMC algorithm converged. To do this, a sample of 250, 000 draws was generated, neglecting the first 50,000. The scale factor was set in order to deliver acceptance rates of between 20 and 30 percent (The acceptance ratio per chains: $26.22 \%$ and $26.28 \%$ ). Convergence was assessed by means of the multivariate convergence statistics taken from Brooks and Gelman (1998). We estimate the model using the Dynare package of Adjemian et al. (2011).

\subsection{Posteriors and Fit of the model}

We fix a small number of parameters commonly used in the literature of real business cycles models: these include $\beta=0.99$ the discount factor, $\delta=0.025$ the quarterly depreciation rate, $\alpha=0.36$ the capital share in the production and the share of steady state hours worked $\bar{H}=1 / 3$. The government expenditures to GDP ratio is set at $24 \%{ }^{12}$ The substitutability between final good varieties $\varepsilon_{P}=10$ is calibrated as in Smets and Wouters (2007), which roughly implies a markup of 11\%. Regarding financial parameters, we fix the net worth-to-capital ratio of entrepreneurs at $\bar{N} / \bar{K}=$ 0.3 as in Gerali et al. (2010). The steady state value of spreads $\left(\bar{R}-\bar{R}^{D}=1.5 / 400\right.$ and $\left.\bar{R}^{L}-\bar{R}^{D}=4.3 / 400\right)^{13}$ and the bank balance sheet $(\bar{D} / \bar{L}=0.46$ and $\overline{B K} / \bar{L}=0.11)$ are calibrated at their respective average values observed in the data. The annual share of insolvent entrepreneurs' projects $1-\bar{\eta}^{E}$ is fixed at $2.5 \%$ and the quarterly cost of monitoring $\mu^{B}$ is 0.12, in line with Bernanke et al. (1999). Following Kolasa (2009), we set the parameter governing the relative size of the core area $n$ at $65 \%$, which is the share implied by nominal GDP levels averaged over the period 1999-2013. The rest of the model is estimated using Bayesian econometrics.

\footnotetext{
${ }^{12}$ On average, Euro Area households consumption represents $56 \%$ of the GDP and investment $20 \%$, then the exogenous spending-GDP ratio is straightforward to derive.

${ }^{13}$ Spreads are set on quarterly basis dividing them by 4 . The steady state interest rates are $\bar{R}=$ $0.01375, \bar{R}^{D}=0.01, \bar{R}^{K}=0.01881$ and $\bar{R}^{L}=0.02075$.
} 


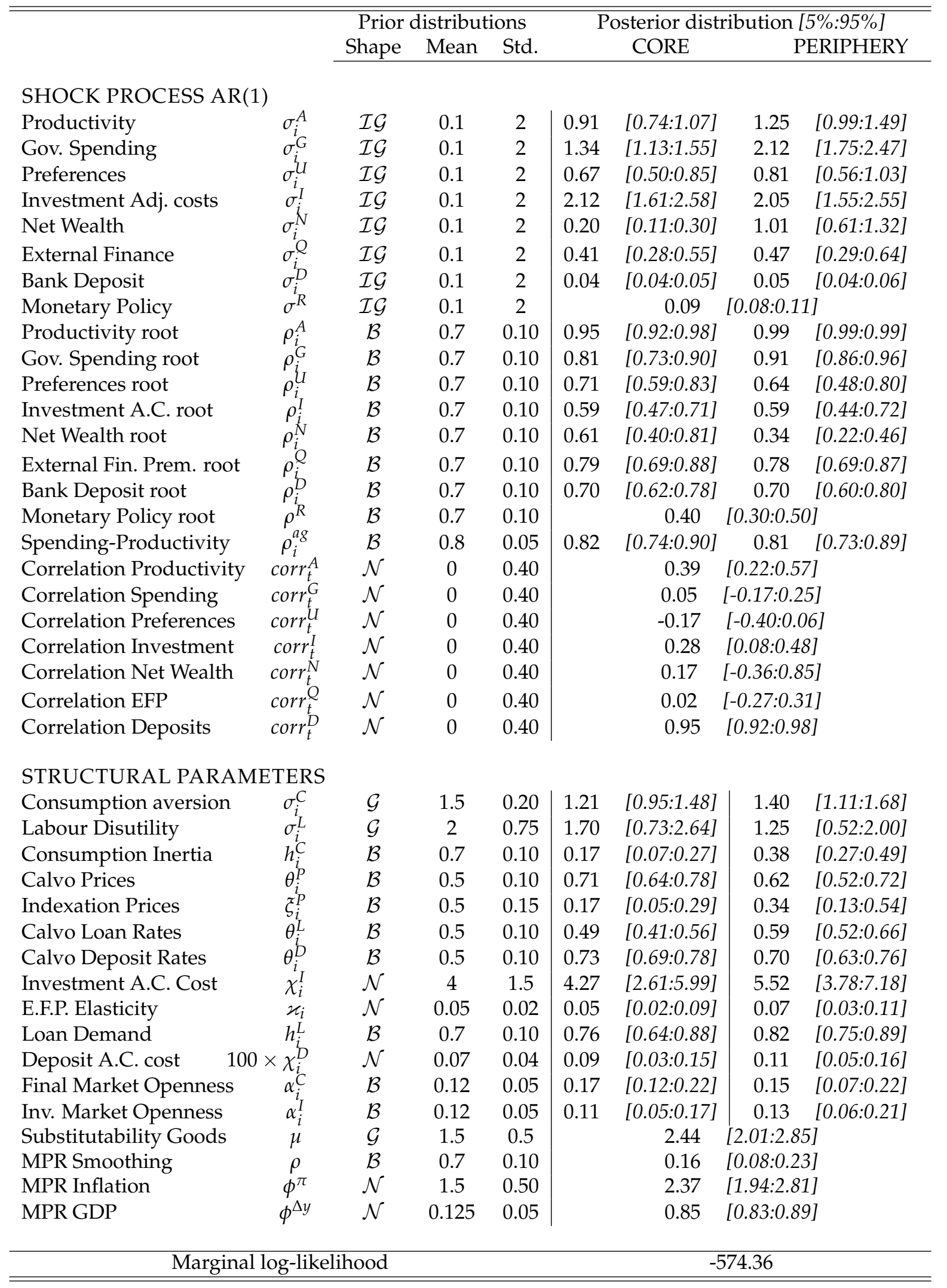

Table 2: Prior and Posterior distributions of structural parameters and shock processes. Note: $\mathcal{I} \mathcal{G}$ denotes the Inverse Gamma distribution, $\mathcal{B}$ the Beta, $\mathcal{N}$ the Normal, $\mathcal{G}$ the Gamma. 
Figure 4 reports the prior and posterior distributions of the parameters. ${ }^{14}$ For a majority of new Keynesian parameters, i.e. $\sigma_{i}^{C}, \sigma_{i}^{L}, h_{i}^{C}, \theta_{i}^{P}, \xi_{i}^{P}, \chi_{i}^{I}, \phi^{\pi}, \phi^{\Delta y}$ and shock process parameters, we use prior distributions close to Smets and Wouters (2003, 2007) and Kolasa (2009). Calvo probabilities are assumed to be around 0.5 for prices, credit rates and deposit rates, which is quite uninformative and rely largely on Smets and Wouters $(2003,2007)$ and Darracq-Pariès et al. (2011). Concerning international macroeconomic parameters, our priors follow Lubik and Schorfheide (2006): for final goods market openness $\alpha_{i}^{C}$ and $\alpha_{i}^{I}$, we choose a beta distribution with prior mean 0,12 and standard deviation $0.05,15$ at last substitutabilities between home/foreign final goods are set to 1.5 with standard deviations of 0.5 . We set the prior for the elasticity of the external finance premium $\varkappa_{i}$ to a beta distribution with prior mean equal to 0.05 and standard deviation 0.02 consistent with previous financial accelerator estimates (Gilchrist et al., 2009a; Bailliu et al., 2015). Adjustment cost on deposits $\chi_{i}^{D}$ is supposed to fluctuate around 0.0007 with a standard deviation of 0.0004 , this prior is in line with Schmitt-Grohé and Uribe (2003). Finally, we estimate the cross-country correlation between structural shocks to capture the correlation and co-movements between countries' aggregates. In line with Jondeau and Sahuc (2008) and Kolasa (2009), we set the mean of the prior distribution for the shock correlations between core countries and peripheral countries equal to 0 with a large standard deviation of 0.4 .

All estimated structural parameters are significantly different from zero. Main observed differences between core and peripheral countries originate from both shocks and structural parameters. The estimated standard deviation of shocks is larger in peripheral countries. The persistence of shocks is similar between countries except for the net wealth shock: entrepreneurs' net wealth in peripheral countries experiences larger and more volatile innovations. The desynchronization of business cycles is also driven by price and interest rate stickiness, capital demand habits and investment adjustment costs. The transmission of monetary policy is not symmetric, particularly on the credit market, as interest rate stickiness is higher in the periphery.

To assess how well the model fits the data, we present in Table 3 the second moments of the observable variables and their counterpart in the model. The model does reasonably well in explaining the standard deviation of all variables except for deposit rates, despite allowing for different degrees of nominal rigidities via the introduction of Calvo contracts. Our model incorporates an imperfect credit market with real rigidities, in this way the model does a good job in predicting the standard deviation and persistence of investment and credit in both area.

\footnotetext{
${ }^{14}$ The posterior distribution combines the likelihood function with prior information. To calculate the posterior distribution to evaluate the marginal likelihood of the model, the Metropolis-Hastings algorithm is employed. We compute the posterior moments of the parameters using a sample of generated 250,000 while, neglecting the first 50,000. The scale factor was set in order to deliver acceptance rates of between 20 and 30 percent (The acceptance ratio per chains: $26.22 \%$ and $26.28 \%$ ). Convergence was assessed by means of the multivariate convergence statistics taken from Brooks and Gelman (1998). We estimate the model using the dynare package Adjemian et al. (2011).

${ }^{15}$ The intra-zone openness is calculated by Eyquem and Poutineau (2010) at $\alpha_{c}^{I}=\alpha_{p}^{I}=0.04$ and $\alpha_{c}^{C}=\alpha_{p}^{C}=0.09$. Ours priors are chosen to be near these values.
} 

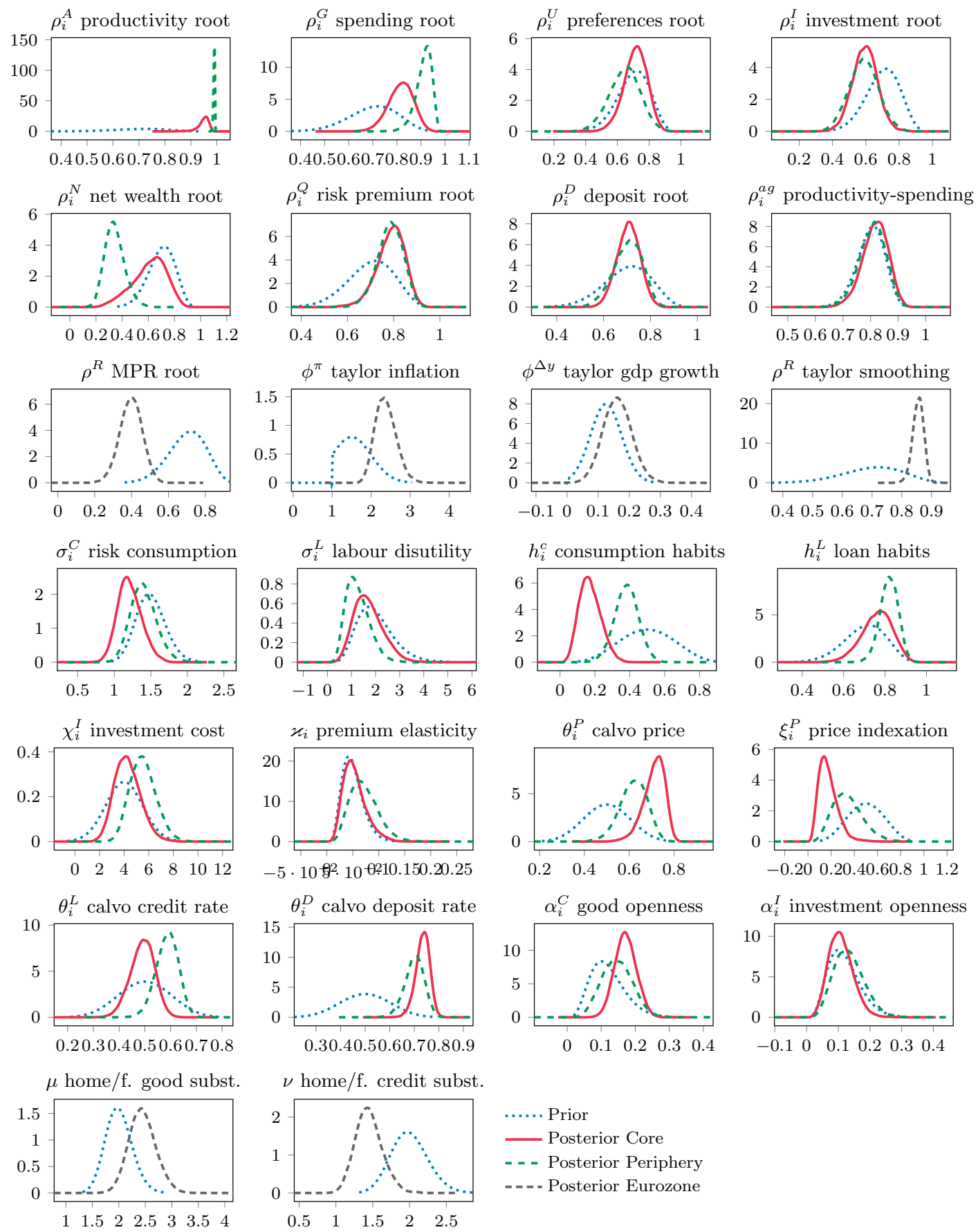

...... Prior

— Posterior Core

- - - Posterior Periphery

- - - - Posterior Eurozone

Figure 4: Prior and posterior distributions of parameters.

\begin{tabular}{lccccccc}
\hline \hline & \multicolumn{8}{c}{ 2nd Moments - Standard Deviation } \\
& $\Delta Y_{i, t} \Delta C_{i, t}$ & $\Delta I_{i, t} \Delta L_{i, t}^{s}$ & $\pi_{i, t}^{C}$ & $R_{i, t}^{L}$ & $R_{i, t}^{D}$ \\
\cline { 2 - 8 } Empirical - core & 0.78 & 0.60 & 1.66 & 1.25 & 0.30 & 1.00 & 0.36 \\
Theoretical - core & 0.72 & 0.68 & 1.68 & 1.50 & 0.42 & 1.28 & 0.78 \\
Empirical - periphery & 0.94 & 0.91 & 2.08 & 2.25 & 0.36 & 0.76 & 0.34 \\
Theoretical - periphery & 0.86 & 0.91 & 1.92 & 2.31 & 0.45 & 1.57 & 0.82 \\
\hline \hline
\end{tabular}

Table 3: Empirical and Theoretical Standard deviations 


\section{An assessment of Macroprudential Policy}

\subsection{Benchmark results}

Policy evaluation is based on a second order approximation of equilibrium conditions of the model using estimated parameters of Figure 4 at their posterior mean. ${ }^{16}$ Table 4 provides a ranking of implementation schemes based on the per capita unionwide level welfare increase expressed in permanent consumption equivalent with respect to the benchmark of the estimated Taylor rule. Figures in brackets report increases in permanent consumption equivalent with respect to the benchmark of an optimal interest rate rule.

As a first result, the optimized coefficients of the Taylor rule suggest stronger responses to Eurozone inflation than the estimated coefficients. This result is in line with Schmitt-Grohé and Uribe (2007) and Quint and Rabanal (2014). Turning to optimized macroprudential parameters, we find that the two regions of the monetary union should be contrasted. Namely, estimated parameters are much higher for peripheral countries (either $\phi_{p}=0.13$ when applied to the global evolution of loans in the Eurozone, or $\phi_{p}=0.15$ when applied to regional loan developments). In contrast, core countries do not require any such macroprudential measures based on credit developments (as $\phi_{c}=0$ when applied to regional loan developments). A uniform setting of the macroprudential parameter leads to a parameter value biased towards peripheral countries, imposing a high and inefficient countercyclical policy reaction to core countries loan developments.

Unsurprisingly, macroprudential measures increase welfare at the Eurozone level. Depending on the implementation scheme, welfare gains may represent between $0.0235 \%$ and $0.0372 \%$ of permanent consumption increase with respect to the estimated Taylor rule (welfare gains are more limited when assessed with regards to the benchmark of an optimal monetary policy). Our simulations suggest that conducting macroprudential actions in core countries does not improve welfare, the main driver of this finding lies in the low variance of the net wealth shock for core entrepreneurs. The drivers of welfare improving macroprudential measures are further discussed in the robustness check section.

As reported, solutions based on a heterogeneous reaction of macroprudential instruments always dominate an uniform setting of the macroprudential parameter. This result makes sense as increasing the number of optimized policy parameters necessarily improves Eurozone welfare. Noticeably, the gap between the two opposite situations (1) and (4) is relatively high, as the granular solution increases the per capita permanent consumption of the representative Eurozone agent by $58.29 \%$ with respect to the uniform implementation of macroprudential policy on European average loan developments. In most of the situations, peripheral countries are the main winners following the conduct of macroprudential policy. As an exception,

\footnotetext{
${ }^{16}$ In the quantitative simulation, we first search for weights attached to inflation $\phi^{\pi}$ and GDP growth $\phi^{\Delta y}$ in the Taylor rule that gives the highest unconditional welfare of households. Here, we maintain the autoregressive parameter of the policy rule $\rho$ at its estimated value since it has low effects on welfare. Based on the grid search by 0.01 unit, we limit our attention to policy coefficients in the interval $(1,3]$ for $\phi^{\pi},[0,3]$ for $\phi^{\Delta y}$ as Schmitt-Grohé and Uribe $(2007)$, and in the interval $[0,1]$ for macroprudential instruments $\phi_{c}$ and $\phi_{p}$.
} 


\begin{tabular}{|c|c|c|c|c|c|c|c|c|}
\hline & & \multicolumn{2}{|c|}{$\begin{array}{l}\text { Taylor } \\
\text { Rule }\end{array}$} & \multicolumn{2}{|c|}{$\begin{array}{l}\text { Macro } \\
\text { Prud }\end{array}$} & \multicolumn{3}{|c|}{$\begin{array}{c}\text { Unconditional } \\
\text { Consumption Gains (\%) }\end{array}$} \\
\hline & & $\phi^{\pi}$ & $\phi^{\Delta y}$ & $\phi_{c}$ & $\phi_{p}$ & Union & Core & Periph. \\
\hline & Empirical Monetary Rule & 2.37 & 0.16 & - & - & -0.0196 & -0.0280 & -0.0092 \\
\hline & Optimal Monetary Rule & 3 & 0 & - & - & - & - & - \\
\hline (1) & $\mathcal{M P} \mathcal{P}_{t} \& \phi_{c}=\phi_{p}$ & 3 & 0 & & 07 & $\begin{array}{c}0.0235 \\
{[0.0040]}\end{array}$ & $\begin{array}{c}0.0274 \\
{[-0.0010]}\end{array}$ & $\begin{array}{c}0.0188 \\
{[0.0100]}\end{array}$ \\
\hline (2) & $\mathcal{M} \mathcal{P}_{t} \quad \& \quad \phi_{c} \neq \phi_{p}$ & 3 & 0 & 0 & 0.13 & $\begin{array}{c}0.0302 \\
{[0.0110]}\end{array}$ & $\begin{array}{c}0.0216 \\
{[-0.0060]}\end{array}$ & $\begin{array}{c}0.0407 \\
{[0.0320]}\end{array}$ \\
\hline (3) & $\mathcal{M} \mathcal{P}_{i, t} \quad \& \quad \phi_{c}=\phi_{p}$ & 3 & 0 & & 09 & $\begin{array}{c}0.0296 \\
{[0.0100]}\end{array}$ & $\begin{array}{c}0.0197 \\
{[-0.0083]}\end{array}$ & $\begin{array}{c}0.0418 \\
{[0.0325]}\end{array}$ \\
\hline (4) & $\mathcal{M} \mathcal{P}_{i, t} \quad \& \quad \phi_{c} \neq \phi_{p}$ & 3 & 0 & 0 & 0.15 & $\begin{array}{c}0.0372 \\
{[0.0180]}\end{array}$ & $\begin{array}{c}0.0212 \\
{[-0.0070]}\end{array}$ & $\begin{array}{c}0.0570 \\
{[0.0480]}\end{array}$ \\
\hline
\end{tabular}

Note: Wefare gains are expressed in permanent consumption equivalent with respect to the benchmark of the estimated Taylor rule, figures in brackets report increases in permanent consumption equivalent with respect to the benchmark of an optimal interest rate rule.

Table 4: Welfare-based performances of optimal simple macroprudential rules

the implementation of macroprudential measures set uniformly on global loan developments leads to the worst situation, as union-wide averages dampen the level of financial imbalances with respect to the actual situation of this group of countries. The welfare gap between the two extreme situations (1) and (4) is much higher for peripheral countries than the one encountered for Eurozone averages. In contrast, core countries only marginally gain from the implementation of macroprudential measures. The best increase in permanent consumption observed in the granular situation (4), only represents $37 \%$ of the value reached by peripheral countries. More critically, contrasting the welfare consequences of the granular situation (4) with the equilibrium reached if the central bank implements an optimal interest rate rule, clearly shows that core countries are worse-off in this situation, as welfare may decrease by $0.007 \%$, thus creating a caveat questioning the interest of adopting coordinated macroprudential measures with peripheral countries.

\subsection{Sensitivity analysis}

In the rest of the paper, we assess the stability of the two optimal policy outcomes (2) and (4) displayed in Table 4 with respect to parameters related to the financial component of the model (optimism of entrepreneurs and rigidity in interest rates), with respect to policy considerations (value of parameters in the Taylor Rule, Pecking order in the choice of macroprudential measures) and with respect to the period of estimation of the model. For all experiments reported in Table 5, Table 6 and Table 7, we find that the ranking between the two types of policies is kept unchanged.

As reported, for all cases, the reaction of macroprudential instruments to regional developments leads to higher welfare improvements. Nevertheless, the aggregate 


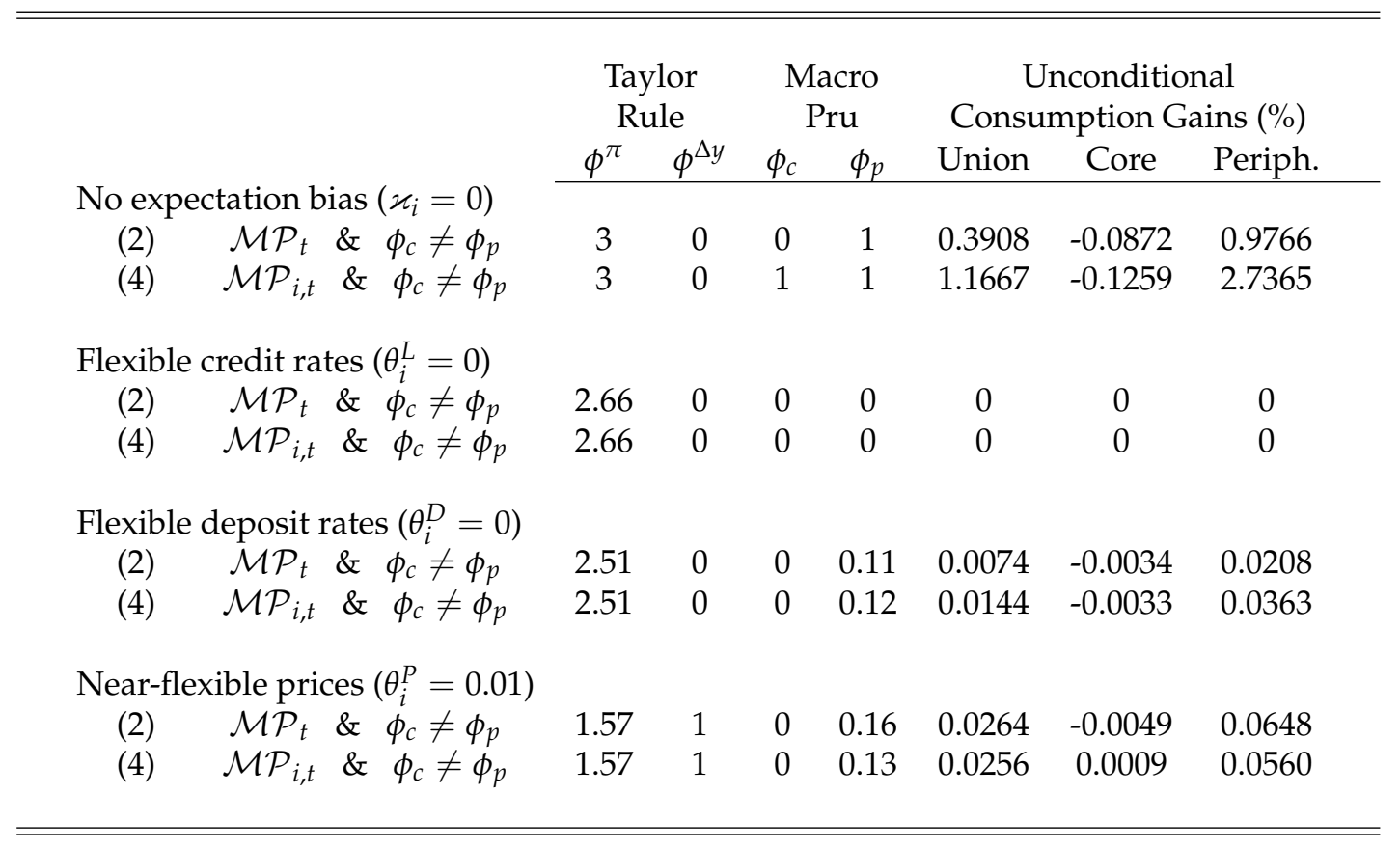

Table 5: Sensitivity analysis of macroprudential stances to financial frictions

welfare increase reached at the union-wide level fluctuates quite much, as it ranks from -0.0047 (in the case of a pecking order policy where periphery moves first) to 0.3908 (in the case of no expectation bias) for policy (2) and from 0 (in the case of estimation limited to the pre-crisis period) to 1.167 (in the case of no expectation bias) for policy (2). Furthermore, regional outcomes are also affected by the sensitivity experiment, and in some situations, we may observe regional welfare reversals leading to welfare transfers between the two regions of the monetary union.

\section{The role of financial and nominal frictions}

The first series of results reported in Table 5 focuses on the parameters related to the financial component of the model. In the first part of the table, the absence of bias in the expectations of entrepreneurs (namely, imposing $\varkappa_{i}=0$ ) requires tighter macroprudential policy actions. At a first sight, this result may be rather surprising as one could expect that an over-expectation of entrepreneur's outcomes may lead to over-borrowing. This, in turn would create greater damages to the economy and, by so, would imply more pronounced macroprudential policy measures. Instead, the absence of optimism has opposite effects according to the type of shock: it dampens standard demand and supply shocks but exacerbates financial shocks. In this later situation, the transmission channel of the financial shock through the external finance premium disappears, leading to a larger adjustment of the economy though the quantities of loans and output, rather than in the rate of return on capital. The larger effects coming from a financial shock require a stronger reaction from macroprudential authorities. ${ }^{17}$

\footnotetext{
${ }^{17}$ In further sensitivity experiments, removing both firms' optimism and financial shocks, our model reveals that macroprudential policy is passive, as the equilibrium of the model is character-
} 
Another series of results reported in Table 5 focuses on the consequences of interest rate stickiness. As observed, the sensitivity analysis devoted to the staggered setting of lending interest rates clearly underlines the role of macroprudential policy in overcoming inefficiencies arising from their stickiness: when lending interest rates are fully flexible (namely, $\theta_{i}^{L}=0$ ), macroprudential policy does no longer improve welfare with respect to the benchmark of an optimal monetary policy. This result makes sense, as sticky interest rates are not able to transmit the business cycles developments to borrowers and may thus lead to either under or over borrowing decisions incurring welfare losses. In this situation, macroprudential measures are able to foster interest rate adjustments that affect lending decisions and lead to welfare gains. Put differently, our model reveals that in this case macroprudential policy is passive, as the equilibrium of the model is characterized by an optimal macroprudential stance equal to zero. Flexible rates on deposits (namely $\theta_{i}^{D}=0$ ) decrease welfare gains with respect to the benchmark situation. However, there are still welfare gains, as the major friction regarding the staggered interest rate on loans is not corrected.

Finally, the last situation reported in Table 5 focuses on near flexible prices $\left(\theta_{i}^{P}=\right.$ 0.01). This sensitivity exercise has two main consequences on the model: it suppresses a nominal friction (thus reducing the effect of macroeconomic policies on the general equilibrium of the model) and it imposes a symmetric price adjustment mechanism between the two regions of the Eurozone. The first effect clearly explains the decrease in welfare gains. The second effect has another interesting property: by imposing an homogenous speed of price adjustment in all the regions of the Eurozone, we find that a macroprudential policy reacting to union-wide financial developments leads to almost the same welfare gains in the monetary union than instruments tailored to regional financial developments (respectively 0.0264 and 0.0256). Thus, asymmetries in the adjustment of prices seem to be an important factor that shapes the transmission of macroprudential measures and makes the choice of a reaction to regional financial developments worthwhile.

\section{The role of the policy environment}

The second series of sensitivity experiments conducted in Table 6 reports robustness checks related to the policy environment. We more particularly evaluate how restrictions set on the design of the optimal policy drive our results and may lead to welfare reversals. We successively consider the sensitivity of our results to assumptions related to the objective function, the benchmark situation of an optimal monetary policy, the homogeneity of the Taylor rule over the whole monetary union and the pecking order in the optimization of regional macroprudential policy parameters.

In the first item of Table 6, we evaluate how the zero lower bound parameter $\lambda^{R}$ affects welfare outcomes. Even if in the benchmark calibration our model does not hit the zero lower bound, accounting for this possibility affects welfare, as the authorities take into account the variability of the interest rate as a determinant of welfare. Ignoring the zero lower bound mechanically leads to more welfare gains reached by the optimal monetary policy, thus leaving less role for macroprudential

ized by an optimal macroprudential stance equal to zero. 


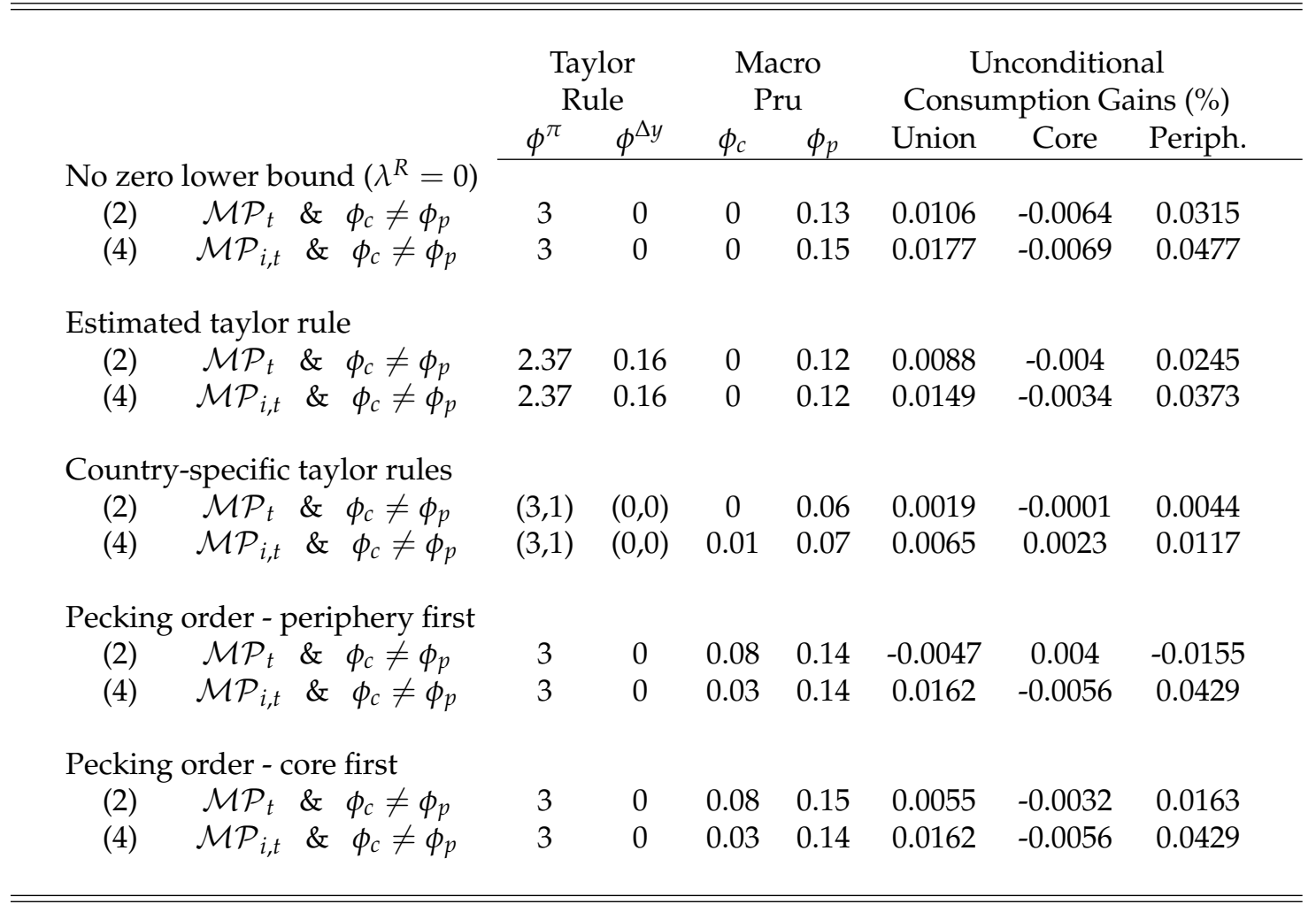

Table 6: Robustness checks to policy rule assumptions

policy to affect welfare gains. Thus as clearly reported, we find that in this case the union-wide welfare increase is much lower, and that it creates welfare transfers from the core to the periphery for both policies (2) and (4).

In the second item of Table 6, we evaluate the sensitivity of welfare gains to the choice of the benchmark monetary policy. In this experiment, we replace the optimal monetary policy benchmark used in the analysis conveyed in Table 4 by an estimated Taylor rule giving less weight to price stability (the Taylor parameter is 2.32 instead of 3 ) and accounting for output growth concerns. As reported the choice of the benchmark has only scale effects on the results without affecting the relative ranking of the two macroprudential policy schemes. However, conducting a non-optimal monetary policy creates international welfare transfers between the two regions of the monetary union so that the core situation clearly deteriorates with respect to the benchmark results reported in Table 4, thus questioning the implementation of macroprudential measures in this part of the monetary union.

In the third item of Table 6, we evaluate the consequences of setting countryspecific Taylor rules to investigate whether macroprudential policy rules are just a substitute to country-adjusted Taylor rules. Even when Taylor rules are set on a national basis, macroprudential policy still plays a role in improving the welfare of the Eurozone with respect to the benchmark situation.

In the fourth item of Table 6 we evaluate the consequences of letting either regions of the monetary union becoming a leader in the choice of the macroprudential 


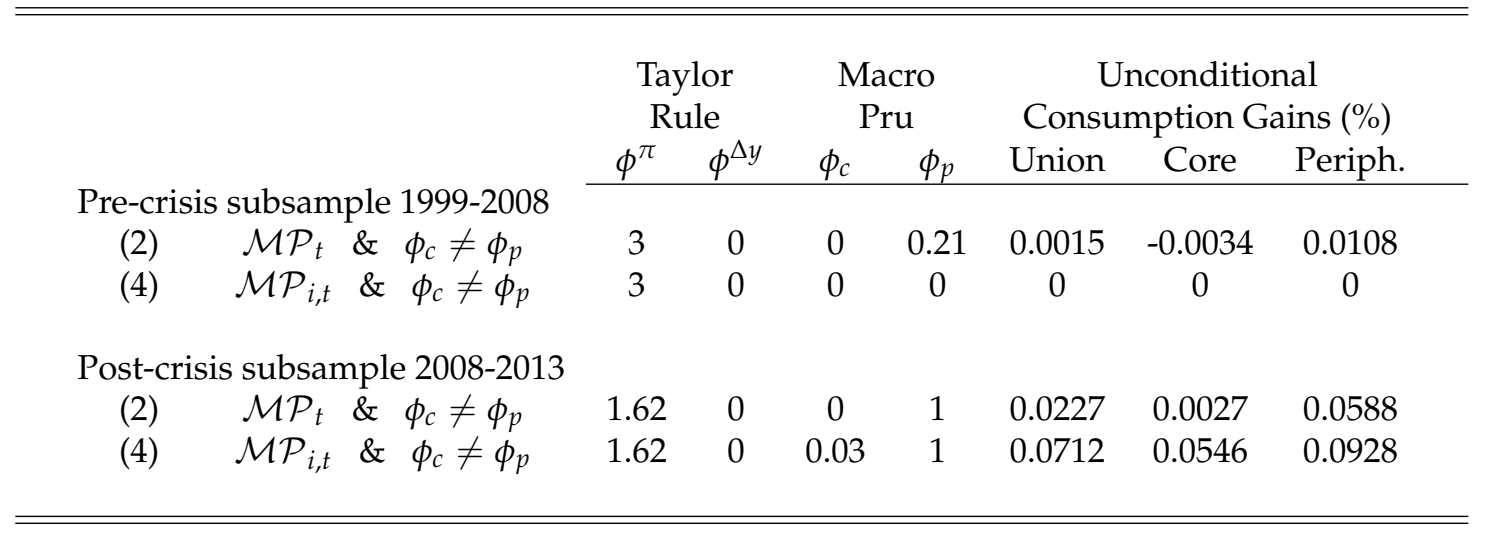

Table 7: Robustness checks to the sample before and after the crisis

policy, leaving the other region to adjust its policy choices. Two situations are successively analyzed depending on the leading region. Unsurprisingly, the welfare gains are clearly lower than the ones obtained in the original policy experiment, as a Stackelberg situation replaces a cooperative setting of macroprudential parameters. Two main results emerge from this outcome: first, if macroprudential policy is conducted with instruments reacting to union-wide developments, the region that moves first incurs welfare losses, creating a welfare transfer towards the rest of the monetary union. In this case, the follower is able to adjust its policy stance in a better way and records welfare gains. Second, when each region adopts a macroprudential instrument that reacts to regional developments, the results are unaffected by the nature of the pecking order, since in all cases, we observe a welfare transfer from the core to the periphery.

\section{The role of structural shifts}

Finally as a last robustness exercise, we analyze whether our results are altered by any structural shift caused by the financial crisis episode. As reported in Table 7, we split the data sample, using 2008Q1 as the cut-off quarter. To avoid any problem related to the weak identification of estimated parameters coming from the very small number of observations in subsamples, we run our welfare simulations using the model estimated at the mode. Results displayed in Table 7 still assume the Stackelberg assumption for monetary-macroprudential policy interactions, as these measures are chosen after monetary policy decisions based on the simple optimal Taylor rule. As observed, splitting the sample slightly affects our results: peripheral countries are always net gainers, while core countries experience welfare losses before the crisis and gains after the crisis. Furthermore, monetary policy appears to be strongly affected by the financial turmoil since the Taylor parameter shrinks to 1.62. This drop may probably come from the zero lower bound faced by the central bank after the crisis. The low interest rates environment since 2008 seems to have exacerbated the effectiveness of macroprudential policy through an increase in the prudential policy stance in periphery and a global welfare improvement for the Eurosystem. 


\section{Conclusion}

This paper has reported significant welfare increases coming from a granular implementation of macroprudential policy tailored to regional developments. However, welfare gains are unequally shared between peripheral and core countries. In the best situation, core countries only gain $37 \%$ of the peripheral welfare increase using the benchmark of an estimated Taylor rule. More critically, they may even be worseoff, with respect to the conduct of an optimal monetary policy conducted at the union level. In terms of policy implications, our experiments reveal that macroprudential policy should be adjusted to the regional level, thus confirming the current institutional framework adopted in the Euro Area based on national macroprudential measures.

Overall, results presented in this paper are a preliminary study of the design of macroprudential policy in an heterogeneous monetary union. Future research should encompass the use of alternative macroprudential instruments more directly adapted to the problem observed by each group of countries to get comparable regional and global welfare gains in a monetary union. In addition, the microfoundation of macroprudential policy is still a missing ingredient in most of macro-models that should deserve further refinement in the next generation of DSGE models.

\section{References}

Adjemian, S., Bastani, H., Juillard, M., Mihoubi, F., Perendia, G., Ratto, M., Villemot, S., 2011. Dynare: Reference manual, version 4. Dynare Working Papers 1.

Angelini, P., Neri, S., Panetta, F., 2014. The interaction between capital requirements and monetary policy. Journal of Money, Credit and Banking 46 (6), 1073-1112.

Bachmann, R., Elstner, S., 2013. Firms' Optimism and Pessimism. CESifo Working Paper Series 4176, CESifo Group Munich.

Bailliu, J., Meh, C., Zhang, Y., 2015. Macroprudential rules and monetary policy when financial frictions matter. Economic Modelling 50, 148-161.

Benes, J., Kumhof, M., Laxton, D., Apr. 2014. Financial Crises in DSGE Models: A Prototype Model. IMF Working Papers 14/57, International Monetary Fund.

Bernanke, B., Gertler, M., Gilchrist, S., 1999. The financial accelerator in a quantitative business cycle framework. Handbook of macroeconomics 1, 1341-1393.

Brooks, S. P., Gelman, A., 1998. General methods for monitoring convergence of iterative simulations. Journal of computational and graphical statistics 7 (4), 434-455.

Darracq-Pariès, M., Kok-Sørensen, C., Rodriguez-Palenzuela, D., 2011. Macroeconomic propagation under different regulatory regimes: Evidence from an estimated dsge model for the euro area. International Journal of Central Banking 7 (4), 49-113.

De Grauwe, P., 2010. The scientific foundation of dynamic stochastic general equilibrium (dsge) models. Public choice 144 (3-4), 413-443.

De Larosière, J., 2009. The high-level group on financial supervision in the eu: report.

Eyquem, A., Poutineau, J.-C., 2010. Markets integration and macroeconomic. dispersion in a monetary union. Recherches économiques de Louvain 76 (1), 5-5. 
Galati, G., Moessner, R., 2013. Macroprudential policy-a literature review. Journal of Economic Surveys $27(5), 846-878$.

Gerali, A., Neri, S., Sessa, L., Signoretti, F. M., 2010. Credit and banking in a dsge model of the euro area. Journal of Money, Credit and Banking 42 (s1), 107-141.

Gilchrist, S., Ortiz, A., Zakrajsek, E., 2009a. Credit risk and the macroeconomy: Evidence from an estimated dsge model. Unpublished manuscript, Boston University.

Gilchrist, S., Sim, J., Zakrajsek, E., 2009b. Uncertainty, credit spreads, and investment dynamics. Tech. rep., Boston University mimeo.

Goodhart, C. A., Sunirand, P., Tsomocos, D. P., 2005. A risk assessment model for banks. Annals of Finance 1 (2), 197-224.

Hirakata, N., Sudo, N., Ueda, K., 2009. Chained credit contracts and financial accelerators. Tech. rep., Institute for Monetary and Economic Studies, Bank of Japan.

Hirakata, N., Sudo, N., Ueda, K., 2011. Do banking shocks matter for the US economy? Journal of Economic Dynamics and Control 35 (12), 2042-2063.

Jeanne, O., Korinek, A., Sep. 2010. Managing Credit Booms and Busts: A Pigouvian Taxation Approach. Working Paper Series 12, Peterson Institute for International Economics.

Jondeau, E., Sahuc, J.-G., 2008. Optimal monetary policy in an estimated dsge model of the euro area with cross-country heterogeneity. International Journal of Central Banking.

Kolasa, M., 2009. Structural heterogeneity or asymmetric shocks? poland and the euro area through the lens of a two-country dsge model. Economic Modelling 26 (6), 1245-1269.

Loisel, O., 2014. Discussion of monetary and macroprudential policy in an estimated dsge model of the euro area. International Journal of Central Banking.

Lubik, T., Schorfheide, F., 2006. A bayesian look at the new open economy macroeconomics. In: NBER Macroeconomics Annual 2005, Volume 20. MIT Press, pp. 313-382.

Poutineau, J.-C., Vermandel, G., 2015a. Cross-border banking flows spillovers in the eurozone: Evidence from an estimated dsge model. Journal of Economic Dynamics and Control 51, 378-403.

Poutineau, J.-C., Vermandel, G., 2015b. Financial frictions and the extensive margin of activity. Research in Economics 69 (4), 525-554.

Quint, D., Rabanal, P., 2014. Monetary and macroprudential policy in an estimated dsge model of the euro area. International Journal of Central Banking 37, 169-236.

Schmitt-Grohé, S., Uribe, M., 2003. Closing small open economy models. Journal of International Economics 61 (1), 163-185.

Schmitt-Grohé, S., Uribe, M., 2007. Optimal simple and implementable monetary and fiscal rules. Journal of Monetary Economics 54 (6), 1702-1725.

Smets, F., Wouters, R., 2003. An estimated dynamic stochastic general equilibrium model of the euro area. Journal of the European Economic Association 1 (5), 1123-1175.

Smets, F., Wouters, R., 2007. Shocks and frictions in us business cycles: A bayesian dsge approach. American Economic Review 97 (3), 586-606.

Woodford, M., 2003. Interest and prices: foundations of a theory of monetary policy. Princeton University Press. 


\section{A Appendix: The Non-Linear Model}

Our model describes a monetary union made of two asymmetric regions $i \in\{c, p\}$ (where $c$ is for core and $p$ for periphery). Each area $i$ of the monetary union is of a relative size $n_{i}$ normalized to 1 with respective size $n$ and $1-n$ for the core and peripheral area. Each country is populated by consumers, intermediate and final producers, entrepreneurs, capital suppliers and a banking system. Regarding the conduct of macroeconomic policy, we assume national fiscal authorities and a common central bank. The implementation of the macroprudential policy is left open, and discussed below. We account for several sources of rigidities to enhance the empirical relevance of the model. The set of real rigidities encompasses consumption habits, investment adjustment costs, loan demand habits. Regarding nominal rigidities, we account for stickiness in final goods prices and loan/deposit interest rates.

Due to the asymmetry between countries, for each variable denoted $X_{i, t}(x)$, we aggregate households, firms, entrepreneurs and banks using the following aggregator for agent $x \in[0,1]$ living in the monetary union:

$$
\mathcal{G}\left(X_{i, t}(x)\right)=\left\{\begin{array}{l}
\int_{0}^{n} X_{c, t}(x) \mathrm{d} x \text { for } i=c \\
\int_{n}^{1} X_{p, t}(x) \mathrm{d} x \text { for } i=p
\end{array} .\right.
$$

\section{A.1 Households}

In each economy there is a continuum of identical households who consume, save and work in intermediate firms. The total number of households is normalized to 1 . The representative household $j$ maximizes the welfare index:

$$
\max _{\left\{C_{i, t}(j), H_{i, t}(j), D_{i, t+1}^{d}(j)\right\}} \mathbb{E}_{t} \sum_{\tau=0}^{\infty} \beta^{\tau} e^{\varepsilon_{i, t+\tau}^{U}}\left[\frac{\left(C_{i, t+\tau}(j)-h_{i}^{C} C_{i, t-1+\tau}\right)^{1-\sigma_{i}^{C}}}{1-\sigma_{i}^{C}}-\chi_{i} \frac{H_{i, t+\tau}^{1+\sigma_{i}^{H}}(j)}{1+\sigma_{i}^{L}}\right],
$$

subject to:

$$
\begin{aligned}
\frac{W_{i, t}}{P_{i, t}^{C}} H_{i, t}(j)+\left(1+R_{i, t-1}^{D}\right) \frac{D_{i, t}^{d}(j)}{P_{i, t}^{C}}+\frac{\Pi_{i, t}(j)}{P_{i, t}^{C}}+\frac{\bar{M}_{i}(j)}{P_{i, t}^{C}}= & C_{i, t}(j)+\frac{D_{i, t+1}^{d}(j)}{P_{i, t}^{C}} \\
& +\frac{T_{i, t}(j)}{P_{i, t}^{C}}+\frac{P_{i, t}}{P_{i, t}^{C}} A C_{i, t}^{D}(j)
\end{aligned}
$$

Here, $C_{i, t}(j)$ is the consumption index, $h_{i}^{C} \in[0,1]$ is a parameter that accounts for external consumption habits, $H_{i, t}(j)$ is labor effort, $\varepsilon_{i, t}^{U}$ is an exogenous $A R(1)$ shock to household preferences. The income of the representative household is made of labor income (with nominal wage, $W_{i, t}$ ), interest payments for deposits, (where $D_{i, t}^{d}(j$ ) stands for the deposit subscribed in period $t-1$ and $1+R_{i, t-1}^{D}$ is the gross nominal rate of interest between period $t-1$ an period $t$ ), and earnings $\Pi_{i, t}(j)$ from shareholdings. ${ }^{18}$ The representative household spends this income on consumption, deposits and tax payments (for a nominal amount of $T_{i, t}(j)$ ). Finally, he has to pay

\footnotetext{
${ }^{18}$ Positive profits are generated from monopolistic competition on intermediate good market.
} 
quadratic adjustment costs to buy new deposit services (Schmitt-Grohé and Uribe, 2003), according to the function, $A C_{i, t}^{D}(j)=0.5 \chi_{i}^{D}\left(D_{i, t+1}^{d}(j)-\bar{D}_{i}^{d}(j)\right)^{2} / \bar{D}_{i}^{d}(j)$, where $\bar{D}_{i}^{d}(j)$ is the steady state level of deposits. In order to make the households/banks deposit problem tractable in the steady state, we assume that households hold a constant quantity of real money balances $\bar{M}_{i}(j)$.

The first order conditions that solve this problem can be summarized with an Euler condition:

$$
\frac{\beta\left(1+R_{i, t}^{D}\right)}{1+P_{i, t} A C_{i, t}^{D \prime}(j)}=\mathbb{E}_{t}\left\{\frac{e^{\varepsilon_{i, t}^{U}}}{e^{\varepsilon_{i, t+1}^{U}}} \frac{P_{i, t+1}^{c}}{P_{i, t}^{c}}\left(\frac{C_{i, t+1}(j)-h_{i}^{C} C_{i, t}}{C_{i, t}(j)-h_{i}^{C} C_{i, t-1}}\right)^{\sigma_{i}^{C}}\right\},
$$

and a labor supply function:

$$
\frac{W_{i, t}}{P_{i, t}^{C}}=\chi_{i} H_{i, t}(j)^{\sigma_{i}^{L}}\left(C_{i, t}(j)-h_{i}^{C} C_{i, t-1}\right)^{\sigma_{i}^{C}}
$$

The consumption basket of the representative household and the consumption price index of country $i$ are:

$$
C_{i, t}(j)=\left(\left(1-\alpha_{i}^{C}\right)^{1 / \mu} C_{h i, t}(j)^{(\mu-1) / \mu}+\left(\alpha_{i}^{C}\right)^{1 / \mu} C_{f i, t}(j)^{(\mu-1) / \mu}\right)^{\mu /(\mu-1)},
$$

and $P_{i, t}^{C}=\left(\left(1-\alpha_{i}^{C}\right) P_{h, t}^{1-\mu}+\alpha_{i}^{C} P_{f, t}^{1-\mu}\right)^{1 /(1-\mu)}$ where $\mu$ is the elasticity of substitution between the consumption of home $\left(C_{h, i, t}(j)\right)$ and foreign $\left(C_{f, i, t}(j)\right)$ goods and $\alpha_{i}^{C}$ is the degree of openness of the economy $i$. In this model, we assume home bias in consumption, so that $\alpha_{i}^{C}<\frac{1}{2}$.

\section{A.2 Firms}

This sector is populated by two groups of agents: intermediate firms and final firms. Intermediate firms produce differentiated goods $i$, choose labor and capital inputs, and set prices according to the Calvo model. Final goods producers act as a consumption bundler by combining national intermediate goods to produce the homogenous final good. ${ }^{19}$

Concerning the representative intermediate firm $i$, it has the following technology:

$$
Y_{i, t}(i)=e^{\varepsilon_{i, t}^{A}} K_{i, t}(i)^{\alpha} H_{i, t}^{d}(i)^{1-\alpha},
$$

where $Y_{i, t}(i)$ is the production function of the intermediate good that combines capital $K_{i, t}(i)$, labor $H_{i, t}^{d}(i)$ and technology $\varepsilon_{i, t}^{A}$ (an $A R(1)$ productivity shock). Intermediate goods producers solve a two-stages problem. In the first stage, taking input prices $W_{i, t}$ and $Z_{i, t}$ as given, firms rent inputs $H_{i, t}^{d}(i)$ and $K_{i, t}(i)$ in a perfectly competitive

\footnotetext{
${ }^{19}$ Final good producers are perfectly competitive and maximize profits, $P_{i, t} Y_{i, t}^{d}-\mathcal{G}\left(P_{i, t}(i) Y_{i, t}(i)\right)$, subject to the production function $Y_{i, t}^{d}=\left(\left(1 / n_{i}\right)^{1 / \epsilon_{p}} \mathcal{G}\left(Y_{i, t}(i)^{\left(\epsilon_{p}-1\right) / \epsilon_{p}}\right)\right)^{\epsilon_{p} /\left(\epsilon_{p}-1\right)}$. We find the intermediate demand functions associated with this problem are, $Y_{i, t}(i)=\left(1 / n_{i}\right)\left(P_{i, t}(i) / P_{i, t}\right)^{-\epsilon_{p}} Y_{i, t}^{d}, \forall i$. where $Y_{i, t}^{d}$ is the aggregate demand.
} 
factor markets in order to minimize costs subject to the production constraint. The first order condition leads to the marginal cost expression:

$$
M C_{i, t}(i)=M C_{i, t}=\frac{1}{e^{\varepsilon_{i, t}^{A}}}\left(\frac{Z_{i, t}}{\alpha}\right)^{\alpha}\left(\frac{W_{i, t}}{(1-\alpha)}\right)^{(1-\alpha)} .
$$

From the cost minimization problem, inputs also satisfy:

$$
\alpha H_{i, t}^{d}(i) W_{i, t}=Z_{i, t} K_{i, t}(i)(1-\alpha) .
$$

In the second-stage, firm $i$ sets the price according to a Calvo mechanism. Each period, firms are allowed to re-optimize its price with probability $\theta_{i}^{P}$ but price increases of $\xi_{i}^{P} \in[0,1]$ at last period's rate of price inflation, while for the other remaining fraction $1-\theta_{i}^{P}$, these firms are able to reset their selling price optimally. The dynamic of prices given these two possible states reads as follows:

$$
P_{i, t}(i)=\left\{\begin{array}{c}
\pi_{i, t-1}^{\xi_{i}^{P}} P_{i, t-1}(i) \text { with probability } \theta_{i}^{P}, \\
P_{i, t}^{*}(i) \text { with probability } 1-\theta_{i}^{P} .
\end{array}\right.
$$

The firm allowed to modify its selling price with a probability $1-\theta_{i}^{P}$ chooses $P_{i, t}^{*}(i)$ to maximize its expected sum of profits:

$$
\max _{\left\{P_{i, t}^{*}(i)\right\}} \mathbb{E}_{t}\left\{\sum_{\tau=0}^{\infty}\left(\theta_{i}^{P} \beta\right)^{\tau} \frac{\lambda_{i, t+\tau}^{c}}{\lambda_{i, t}^{c}}\left[\frac{P_{i, t}^{*}(i)}{P_{i, t+\tau}^{C}} \prod_{k=1}^{\tau} \pi_{i, t+k-1}^{\xi_{i}^{P}}-\frac{M C_{i, t+\tau}}{P_{i, t+\tau}^{C}}\right] Y_{i, t+\tau}(i)\right\},
$$

under the demand constraint:

$$
Y_{i, t+\tau}(i)=\frac{1}{n_{i}}\left(\prod_{k=1}^{\tau} \pi_{i, t+k-1}^{\xi_{i}^{P}} \frac{P_{i, t}^{*}(i)}{P_{i, t+\tau}}\right)^{-\epsilon_{P}} Y_{i, t+\tau}^{d}, \forall \tau>0,
$$

where $Y_{i, t}^{d}$ represents the quantity of the goods produced in country $i$ and $\lambda_{i, t}^{c}$ the household marginal utility of consumption.

\section{A.3 The Banking Sector and the Imperfect Pass-Through of Policy Rate}

The representative bank $b$ in country $i$ collects deposits from households and lends to firms. The balance sheet of the bank reads as follows:

$$
L_{i, t+1}^{s}(b)=D_{i, t+1}(b)+L_{i, t+1}^{R F}(b)+B K_{i, t+1}(b) .
$$

In this expression, $L_{i, t}^{s}$ is the total level of loans supplied by bank $b, D_{i, t}(b)$ is the total level of deposit services offered by bank $b$ of country $i$ to households, $L_{i, t+1}^{R F}(b)$ is the one-period refinancing loans to banks by the ECB and $B K_{i, t+1}(b)$ is the bank capital. The representative bank sets the rate of interest $R_{i, t}^{L}(b)$ and $R_{i, t}^{D}(b)$.

Banks finance heterogeneous investment projects conducted by entrepreneurs, some of these projects are gainful with a probability $\eta_{i, t+1}^{E}$. Following Bernanke et al. 
(1999), if the borrower's project is gainful, the representative bank obtains $\eta_{i, t+1}^{E}(1+$ $\left.R_{i, t}^{L}(b)\right) L_{i, t+1}^{s}(b)$, whereas if the entrepreneur's project is insolvent, the bank must pay auditing costs $\mu^{B}$ to obtain its loan, ${ }^{20}$ thereby the expected value of next period earnings is:

$$
\begin{aligned}
\mathbb{E}_{t} \Pi_{i, t+1}^{B}(b) & =\left[\mathbb{E}_{t} \eta_{i, t+1}^{E}+\left(1-\mu^{B}\right)\left(1-\eta_{i, t+1}^{E}\right)\right]\left(1+R_{i, t}^{L}(b)\right) L_{i, t+1}^{S}(b) \\
& -\left(1+R_{t}\right) L_{i, t+1}^{R F}(b)-\left(1+R_{i, t}^{D}\right) D_{i, t+1}(b) .
\end{aligned}
$$

In this setting, we assume that there is no discrimination between borrowers, so that the representative and risk-neutral bank serves both domestic and foreign entrepreneur without taking into account specificities regarding the national viability of projects. Concerning bank capital, we follow Hirakata et al. (2009) by assuming the law of motion of the net wealth is made of the profits of the previous period:

$$
B K_{i, t+1}(b)=\left(1-\tau_{i}^{B}\right) \Pi_{i, t}^{B}(b),
$$

where $\tau_{i}^{B}$ denotes a proportional tax on the revenues of the bank by national governments. ${ }^{21}$

As in Darracq-Pariès et al. (2011), we take into account the imperfect pass-through of policy rate on bank lending/deposit rates. We suppose that banks set their interest rates on a staggered basis with some degree of nominal rigidity à la Calvo.

\section{Loan supply decisions}

The determination of interest rate on loans is as follows: the representative bank $b$ maximizes expected profit from Equation 28 with respect to $L_{i, t+1}^{s}(b)$ to obtain the expression of the marginal cost of producing new loans:

$$
1+M C_{i, t}^{L}(b)=\frac{\left(1+R_{t}\right)}{\left[1-\mu^{B}\left(1-\mathbb{E}_{t} \eta_{i, t+1}^{E}\right)\right]} .
$$

The representative retail bank $b$ acts monopolistically to provide loans to entrepreneurs. It determines the interest rate on loans contracted by entrepreneurs. Assuming that it is able to modify its loan interest rate with a probability $1-\theta_{i}^{L}$, it chooses $R_{i, t}^{L *}(b)$ to maximize its expected sum of profits:

$$
\max _{\left\{R_{i, t}^{L *}(b)\right\}} \mathbb{E}_{t}\left\{\sum_{\tau=0}^{\infty}\left(\theta_{i}^{L} \beta\right)^{\tau} \frac{\lambda_{i, t+\tau}^{c}}{\lambda_{i, t}^{c}}\left[R_{i, t}^{L *}(b)-M C_{i, t+\tau}^{L}\right] L_{i, t+1+\tau}(b)\right\},
$$

\footnotetext{
${ }^{20} i . e .$, banks recover $\left(1-\mu^{B}\right)\left(1-\eta_{i, t+1}\right)\left(\left(1+R_{i, t}^{L} b\right)\right) L_{i, t+1}^{s}(b)$ : we borrow this shortcut from Benes et al. (2014), which is a tractable and easier way to introduce the loss-given-default $\mu^{B}$ than in the initial framework of Bernanke et al. (1999) where investors have a technology to size the collateral in case of default.

${ }^{21}$ This tax is necessary to solve the model in steady state. In the same vein, Bernanke et al. (1999) and Hirakata et al. (2011) also add a cost/decay parameter in law of motion of the net wealth.
} 
subject to the demand constraint, $L_{i, t+1+\tau}(b)=\left(1 / n_{i}\right)\left(R_{i, t}^{L *}(b) / R_{i, t+\tau}^{L}\right)^{-\epsilon_{L}} L_{i, t+1+\tau}$, $\tau>0$, where $L_{i, t}(b)$ denotes the quantity of differentiated banking loans $b$ that is used in loans packer production. Finally, the interest rate that solves the FOC for the bank that is allowed to modify its interest rate, it is such that:

$$
\mathbb{E}_{t} \sum_{\tau=0}^{\infty}\left(\theta_{i}^{L} \beta\right)^{\tau} \frac{\lambda_{i, t+\tau}^{c}}{\lambda_{i, t}^{c}}\left[R_{i, t}^{L *}(b)-\frac{\epsilon_{L}}{\left(\epsilon_{L}-1\right)} M C_{i, t+\tau}^{L}\right] L_{i, t+1+\tau}(b)=0 .
$$

\section{Deposit supply decisions}

We proceed accordingly for the determination of deposit interest rate. The nominal marginal cost of one unit of deposit denoted by $M C_{i, t}^{D}$ is the same across banks and is related to the ECB refinancing rate:

$$
1+M C_{i, t}^{D}(b)=1+M C_{i, t}^{D}=\left(1+R_{t}\right) .
$$

Assuming sticky deposit rates, the expected sum of profits for the bank that is allowed to modify its interest rate with a probability $1-\theta_{i}^{D}$ can be expressed as:

$$
\max _{\left\{R_{i, t}^{D *}(b)\right\}} E_{t}\left\{\sum_{\tau=0}^{\infty}\left(\theta_{i}^{D} \beta\right)^{\tau} \frac{\lambda_{i, t+\tau}^{c}}{\lambda_{i, t}^{c}}\left[M C_{i, t+\tau}^{D}-R_{i, t}^{D *}(b)\right] D_{i, t+1+\tau}(b)\right\},
$$

under the constraint, $D_{i, t+1+\tau}(b)=\frac{1}{n_{i}}\left(R_{i, t}^{D *}(b) / R_{i, t+\tau}^{D}\right)^{-\mu_{i, t+\tau}^{D} /\left(\mu_{i, t+\tau}^{D}-1\right)} D_{i, t+1+\tau}^{d}, \forall \tau>$ 0 , where $\mu_{i, t}^{D}=\epsilon^{D} /\left(\epsilon^{D}-1\right)+\varepsilon_{i, t}^{D}$ is the time-varying markup subject to the exogenous deposit rate-push shock process $\varepsilon_{i, t}^{D}$. In equilibrium, the following first order condition emerges:

$$
\sum_{\tau=0}^{\infty}\left(\theta_{i}^{D} \beta\right)^{\tau} \frac{\lambda_{i, t+\tau}^{c}}{\lambda_{i, t}^{c}} \frac{1}{\mu_{i, t+\tau}^{D}-1}\left[R_{i, t}^{D *}(b)-\mu_{i, t+\tau}^{D} M C_{i, t+\tau}^{D}\right] D_{i, t+1+\tau}(b)=0 .
$$

\section{A.4 Capital Suppliers}

Capital suppliers are homogeneous and distributed over a continuum normalized to one. The representative capital supplier $k \in[0 ; 1]$ acts competitively to supply a quantity $K_{i, t+1}(k)$ of capital. Investment is costly, i.e. the capital supplier pays an adjustment cost $A C_{i, t}^{I}(k)$ on investment, such that $A C_{i, t}^{I}(k)=0.5 \chi_{i}^{I}\left(e^{\varepsilon_{i, t}^{I}} I_{i, t}(k) / I_{i, t-1}(k)-\right.$ $1)^{2}$ where $\varepsilon_{i, t}^{I}$ is an exogenous adjustment cost shock on investment. The capital stock of the representative capital supplier thus evolves according to:

$$
K_{i, t+1}(k)=\left(1-A C_{i, t}^{I}(k)\right) I_{i, t}(k)+(1-\delta) K_{i, t}(k) .
$$

The capital supplier produces the new capital stock $Q_{i, t} K_{i, t+1}(k)$ by buying the depreciated capital $Q_{i, t}(1-\delta) K_{i, t}(k)$ and investment goods $P_{i, t}^{I} I_{i, t}(k)$ where:

$$
I_{i, t}(k)=\left(\left(1-\alpha_{i}^{I}\right)^{1 / \mu} I_{h i, t}(k)^{(\mu-1) / \mu}+\left(\alpha_{i}^{I}\right)^{1 / \mu} I_{f i, t}(k)^{(\mu-1) / \mu}\right)^{\mu /(\mu-1)},
$$


and:

$$
P_{i, t}^{I}=\left(\left(1-\alpha_{i}^{I}\right)\left(P_{h, t}\right)^{1-\mu}+\alpha_{i}^{I}\left(P_{f, t}\right)^{1-\mu}\right)^{1 /(1-\mu)} .
$$

In this expression, parameter $\mu$ is the elasticity of substitution between domestic and foreign goods in investment and $\alpha_{i}^{I}<0.5$ measures the degree of investment diversification in the monetary union between home and foreign countries. The representative capital supplier chooses $I_{i, t}(k)$ to maximize profits:

$$
\max _{\left\{I_{i, t}(k)\right\}} \mathbb{E}_{t}\left\{\sum_{\tau=0}^{\infty} \beta^{\tau} \frac{\lambda_{i, t+\tau}^{c}}{\lambda_{i, t}^{c}}\left[Q_{i, t}\left(1-A C_{i, t}^{I}(k)\right)-P_{i, t}^{I}\right] I_{i, t}(k)\right\},
$$

where $\beta^{\tau} \lambda_{i, t+\tau}^{c} / \lambda_{i, t}^{c}$ is the household stochastic discount factor. The price of capital renting thus solves:

$$
Q_{i, t}=P_{i, t}^{I}+Q_{i, t} \frac{\partial\left(I_{i, t}(k) A C_{i, t}^{I}(k)\right)}{\partial I_{i, t}(k)}+\beta \mathbb{E}_{t} \frac{\lambda_{i, t+1}^{c}}{\lambda_{i, t}^{c}} Q_{i, t+1} \frac{\partial\left(I_{i, t+1}(k) A C_{i, t+1}^{I}(k)\right)}{\partial I_{i, t}(k)} .
$$

Thus, the real return from holding one unit of capital from $t$ to $t+1$ is determined by:

$$
\mathbb{E}_{t} \frac{\left(1+R_{i, t+1}^{k}\right)}{\pi_{i, t+1}^{c}}=\mathbb{E}_{t}\left[\frac{Z_{i, t+1} / P_{i, t+1}^{C}+(1-\delta) Q_{i, t+1} / P_{i, t+1}^{C}}{Q_{i, t} / P_{i, t}^{C}}\right]
$$

\section{A.5 Governments}

National governments finance public spending by charging proportional taxes on the bank capital $\tau_{i}^{B}$, net wealth of entrepreneurs $\tau_{i}^{E}$ and by receiving a total value of taxes $\mathcal{G}\left(T_{i, t}(j)\right)$ from households. The budget constraint of the national government is determined by:

$$
\mathcal{G}\left(T_{i, t}(j)\right)+\tau_{i}^{E} \mathcal{G}\left(N_{i, t}(e)\right)+\tau_{i}^{B} \mathcal{G}\left(B K_{i, t}(b)\right)=P_{i, t} G_{i, t}=P_{i, t} \bar{G} \varepsilon_{i, t}^{G}
$$

where $G_{i, t}$ is the total amount of public spending in the $i^{\text {th }}$ economy that follows an AR(1) shock process. Following Smets and Wouters (2007), we assume that exogenous spending is affected by the productivity shock at a degree $\rho_{i}^{a g}$ such that $\varepsilon_{i, t}^{G}=\rho_{i}^{G} \varepsilon_{i, t-1}^{G}+\eta_{i, t}^{G}+\rho_{i}^{a g} \eta_{i, t}^{A}$. The government demand for home goods is, $G_{i, t}(i)=$ $\left(P_{i, t}(i) / P_{i, t}\right)^{-\epsilon_{P}} G_{i, t}$.

\section{A.6 The welfare index}

In each country, we compute the fraction of consumption stream from alternative monetary policy regime to be added (or subtracted) to achieve the benchmark reference. The welfare of aggregate households in country $i$ can be expressed as:

$$
\mathcal{W}_{i, t}=\sum_{\tau=0}^{\infty} \beta^{\tau} \mathcal{U}_{i}\left(C_{i, t+\tau}, H_{i, t+\tau}\right), i=\{c, p\}
$$

where the utility function is defined by:

$$
\mathcal{U}_{i}\left(C_{i, t}, H_{i, t}\right)=e^{\varepsilon_{i, t}^{U}}\left(\frac{\left(C_{i, t}-h_{i}^{C} C_{i, t-1}\right)^{1-\sigma_{i}^{C}}}{1-\sigma_{i}^{C}}-\chi_{i} \frac{H_{i, t}^{1+\sigma_{i}^{H}}}{1+\sigma_{i}^{H}}\right)-\lambda^{R}\left(R_{t}-\bar{R}\right)^{2}
$$


Following Woodford (2003) and Darracq-Pariès et al. (2011), we account for the zero lower bound by adding to the utility function a term $\lambda^{R}\left(R_{t}-\bar{R}\right)^{2}$ that makes the probability of hitting the zero lower bound shrink. Assuming that the Eurosystem authorities are concerned by the mean welfare of the two countries, we defined the welfare objective $\mathcal{W}_{t}$ of the monetary union by the arithmetical average according to the size of each area composing the union:

$$
\mathcal{W}_{t}=n \mathcal{W}_{c, t}+(1-n) \mathcal{W}_{p, t}
$$

After solving the model under regime $a$ and $b$ using 10,000 draws generated by the model for each regime, we obtain the asymptotic mean $E$ [.] of $\mathcal{J}_{c, t}^{b}, \mathcal{J}_{p, t}^{b}, \mathcal{W}_{c, t}^{a}$ and $\mathcal{W}_{p, t}^{a}$. We measure the welfare cost in percentages by finding the value of $\psi \times 100$ that solves:

$$
\begin{aligned}
n E\left[\mathcal{W}_{c, t}^{a}\right]+(1-n) E\left[\mathcal{W}_{p, t}^{a}\right] & =n\left((1-\psi)^{1-\sigma_{c}^{c}}\left(E\left[\mathcal{W}_{c, t}^{b}\right]+E\left[\mathcal{J}_{c, t}^{b}\right]\right)-E\left[\mathcal{J}_{c, t}^{b}\right]\right) \\
& +(1-n)\left((1-\psi)^{1-\sigma_{p}^{c}}\left(E\left[\mathcal{W}_{p, t}^{b}\right]+E\left[\mathcal{J}_{p, t}^{b}\right]\right)-E\left[\mathcal{J}_{p, t}^{b}\right]\right)
\end{aligned}
$$

where $\mathcal{J}_{i, t}^{b}$ is an auxiliary variable defined by:

$$
\left\{\begin{array}{l}
\mathcal{J}_{c, t}^{b}=\frac{\chi_{c}}{1+\sigma_{c}^{H}} e^{\varepsilon_{c, t}^{U}}\left(H_{c, t}^{b}\right)^{1+\sigma_{c}^{H}}+\lambda^{R}\left(R_{t}^{b}-\bar{R}\right)^{2}+\beta \mathbb{E}_{t} \mathcal{J}_{c, t+1}^{b} \\
\mathcal{J}_{p, t}^{b}=\frac{\chi_{p}}{1+\sigma_{p}^{H}} e^{\varepsilon_{p, t}^{U}}\left(H_{p, t}^{b}\right)^{1+\sigma_{p}^{H}}+\lambda^{R}\left(R_{t}^{b}-\bar{R}\right)^{2}+\beta \mathbb{E}_{t} \mathcal{J}_{p, t+1}^{b}
\end{array}\right.
$$

We cannot find an analytical solution of the problem, we use Matlab solver to get the numerical solution. In our quantitative simulations, regime $a$ is the benchmark reference (i.e. the estimated rule or the optimized Taylor rule) while regime $b$ is the model solved with a macroprudential policy. 